Driven to succeed? Teenagers' drive, ambition and performance on high-stakes examinations

John Jerrim Nikki Shure Gill Wyness

Department of Quantitative Social Science Working Paper No. 20-03

July 2020 


\section{Disclaimer}

Any opinions expressed here are those of the author(s) and not those of the UCL Institute of Education. Research published in this series may include views on policy, but the institute itself takes no institutional policy positions.

DoQSS Workings Papers often represent preliminary work and are circulated to encourage discussion. Citation of such a paper should account for its provisional character. A revised version may be available directly from the author.

Department of Quantitative Social Science, UCL Institute of Education, University College London,

20 Bedford Way, London WC1H 0AL, UK 


\title{
Institute of Education
}

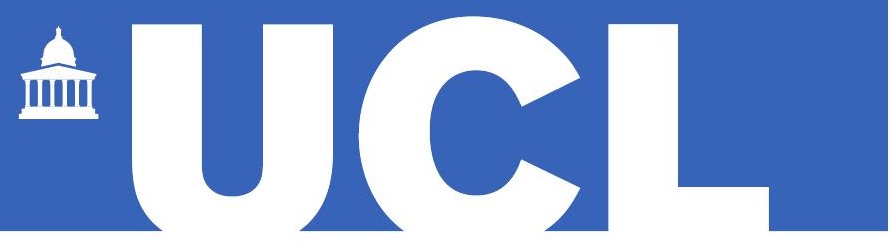

\section{Driven to succeed? Teenagers' drive, ambition and performance oh high-stakes examinations}

\author{
John Jerrim $^{1}$, Nikki Shure ${ }^{2}$, and Gill Wyness ${ }^{3}$
}

\begin{abstract}
$\underline{\text { Abstract }}$
There has been much interest across the social sciences in the link between young people's socio-emotional (non-cognitive) skills and their educational achievement. But much of this research has focused upon the role of the Big Five personality traits. This paper contributes new evidence by examining two inter-related non-cognitive factors that are rarely studied in the literature: ambition and drive. We use unique survey-administrative linked data from England, gathered in the lead-up to highstakes compulsory school exams, which allow us to control for a rich set of background characteristics, prior educational attainment and, unusually, school fixed effects. Our results illustrate substantial gender and immigrant gaps in young people's ambitiousness, while the evidence for socio-economic differences is more mixed. Conversely, we find a strong socio-economic gradient in drive, but no gender gap. Both academically ambitious and driven teenagers achieve grades around 0.37 standard deviations above their peers, even controlling for prior academic attainment and school attended.
\end{abstract}

JEL Codes: $124, \mathrm{~J} 24$

Keywords: socio-economic gaps, gender gaps, aspirations, secondary school, higher education

Acknowledgements: : This research was based on information collected as part of the Programme for International Student Assessment (PISA) 2015 cycle, which was sponsored by the Department for Education. The data are Crown copyright. The support of the Economic and Social Research Council, the Office for Students and Research England (grant reference ES/M010082/1) is gratefully acknowledged along with support from the ESRC/OFSRE Centre for Global Higher Education (CGHE), UCL Institute of Education, London. This work has also been supported by a British Academy Small Grant (SG163113).

\footnotetext{
${ }^{1}$ Department of Social Science, UCL Institute of Education, University College London, 20 Bedford Way London, WC1H OAL. E-mail: j.jerrim@ucl.ac.uk (John Jerrim).

${ }^{2}$ Department of Social Science, UCL Institute of Education, University College London, 20 Bedford Way London, WC1H OAL and Institute of Labor Economics (IZA), Schaumburg-Lippe-Str. 5-9, D53113 Bonn. E-mail: nikki.shure@ucl.ac.uk (Nikki Shure). Corresponding author.

${ }^{3}$ Centre for Education Policy and Equalising Opportunities (CEPEO), UCL Institute of Education, University College London, 20 Bedford Way London, WC1H OAL. E-mail: g.wyness@ucl.ac.uk (Gill Wyness).
} 


\section{Introduction}

A key goal of policymakers across the world is to enhance the knowledge, skills and educational achievement of youth. Developing a better understanding of the correlates and causes of educational achievement has hence become a staple of applied social science research. Although a host of school, family and individual factors have been explored over the years (Hattie 2009), there has been much recent interest in the role played by socio-emotional (i.e. "non-cognitive") skills (Almlund et al. 2011; Borghans et al. 2008). Much of this work has focused upon the relationship between educational achievement and the "Big Five" personality traits of openness, conscientiousness, extroversion, agreeableness and neuroticism (Goldberg 1990). Yet two interrelated socio-emotional skills that have perhaps received somewhat less attention are "ambition" - the extent to which one's goals are ambitious, and "drive" - the extent that one pushes themselves to the maximum of one's abilities in order to reach these very ambitious goals. This paper hence aims to add new evidence on this matter. Specifically, it investigates differences in ambition and drive of teenagers from different demographic backgrounds, before establishing how these key socio-emotional skills are linked to high-stakes educational outcomes.

We view drive and ambition as key socio-emotional skills on the basis of motivation theory (Atkinson 1964) with a specific interest in achievement goal theory (Conroy, Elliot, and Thrash 2009). Elliot and Dweck (1983) popularised the concept of goals in achievement motivation theory. They focus on two types of goals, with a differentiation between "performance goals" (gaining a favourable judgement of competency) and "learning goals" (improving competencies) (Elliot and Dweck 1983). Those individuals who set learning goals tend to be "mastery-oriented" instead of "helpless" in their behavioural responses to challenges, which helps them succeed in a variety of domains (Dweck and Leggett 1988). This mastery-oriented mindset and its learning goals are closely related to the measures of drive and ambition used in this paper.

Understanding the link between socio-emotional factors, such as drive and ambition, and academic outcomes is important from a policy perspective. A small economics literature emphasises the importance of social skills for both future academic attainment and labour market outcomes (e.g. (Long 1995; Bowles, Gintis, and Osborne 2001; Heckman, Stixrud, and Urzua 2006; Carneiro, Crawford, and Goodman 2007; Hilmer and Hilmer 2012). Chowdry, Crawford, and Goodman (2011) show that while two fifths of the socio-economic gap in attainment at age 16 can be accounted for by attainment at age 11, differences in the attitudes and behaviours of young people and their parents during the teenage years also plays a key role. This suggests that while raising the 
early lifetime skills of young people from poor families is likely to be a highly effective means of closing the SES attainment gap, policies that aim to reduce differences in attitudes and behaviours between the poorest children and those from better-off backgrounds during the teenage years may also be important.

A handful of existing studies, primarily conducted by psychologists, have examined the link between drive (Lynn 1959; Wong and Csikszentmihalyi 1991; Tuckman 1999) or ambition (Plucker and Quaglia 1998; Stankov et al. 2012) and young people's academic achievement. These studies, from across a range of countries, have confirmed the positive relationship between ambition/drive and academic performance. They have, however, tended to be based upon small samples and/or specific subgroups. While these few studies have explicitly examined drive and ambition, many have explored other related socio-emotional traits. These are reviewed in a meta-analysis by Hattie (2009), who finds that while the relationship between personality and achievement is close to zero, "the relationships of self-efficacy, self-concept, aspects of motivation, and persistence with achievement, however, are among the larger correlates". He finds an effect size (Cohen's d) of 0.48 for the 327 studies that explore the relationship between motivation and achievement. The same is true for the 148 studies in five meta-analyses that focus upon concentration and engagement (Cohen's $d=0.48$ ) (Hattie 2009). A related meta-analysis found that self-belief has a small effect (0.08 standard deviations) on academic achievement conditional on prior attainment (Valentine, DuBois, and Cooper 2004). Other work has linked ambitious occupational aspirations to performance on the Programme for International Student Assessment (PISA), finding a positive association with academic achievement (Barone 2006). This cross-national work uses cross-sectional data and is thus not able to account for prior academic attainment.

There are two notable gaps in this evidence base. First, there is currently limited evidence about how individual's ascribed background characteristics (gender, immigrant, socio-economic status) are linked to the drive and ambition of teenagers. For instance, are young people from disadvantaged backgrounds less driven to succeed than their more affluent peers, and to what extent might this explain socio-economic gaps in educational achievement? Likewise, are young women less driven and ambitious than young men, which could in turn be related to the gender pay gap? Second, do drive and ambition influence performance on high-stakes educational examinations - or are these socio-emotional competencies simply capturing the effect of other unmeasured/unobserved variables (e.g. prior academic ability)? Most previous work conducted in this area has only focused upon "low-stakes" outcomes (e.g. tests that do not have any 
consequences if the young person passes or fails) and typically include only a limited set of background controls with limited information on schools (Hattie 2009). It hence remains uncertain as to whether drive and ambition really have a causal impact upon important educational outcomes. By using an extremely rich set of background characteristics, prior attainment controls and school fixed effects, our study moves closer to estimating a causal effect of ambition and drive on outcomes than other studies in the existing literature.

This paper aims to strengthen the evidence base in these areas via analysis of the 2015 round of the PISA dataset for England which has been linked to young people's administrative education records (Department for Education 2017a). A unique feature is that these data have been collected at a critical point in young people's schooling, at age 15/16, just six-months before they sit important, high-stakes national examinations and make key decisions about their future (e.g. whether to stay in school, which subjects to take in their age 18 examinations, which will determine university entry). At the same time, as 15/16-year-olds, it is also a time of growing distractions (e.g. boy/girlfriends, experimenting with drugs or alcohol) which may influence their academic motivations. The data hence refer to a setting when remaining ambitious and driven is likely to be critical, with potentially important consequences for the rest of young people's lives.

Using these data, we first consider the characteristics of young people who describe themselves as driven and ambitious, defining drive according to pupils responses to a battery of survey questions, and defining ambition according to pupils' educational plans (with ambitious pupils defined as those planning to apply to Oxford or Cambridge - two of the world's most prestigious universities). We then investigate the strength of the association between drive/ambition and academic performance in the high-stakes GCSE examinations. Critically, we are able to include in our models an unusually rich array of controls, including multiple measures of prior achievement, socio-economic background, other non-cognitive skills and school fixed-effects. The latter is an important addition to the literature - given that socio-emotional skills are typically picked up in survey data, per school sample sizes are typically too restrictive to support school fixed-effects models. However, the dataset we use (explained in more detail in the next section) contains a large number of schools (206) and pupils within schools (42 per school) - ensuring this is possible. Consequently, although any causal claim continues to rest upon a selection-upon-observables assumption (as is typical - and largely unavoidable - in this literature) our estimates are likely to be free from the influence of the major confounders that plague most existing work in this area, including school factors. 
Our results suggest that boys hold much more ambitious educational plans than girls, even when they attend the same school, come from similar family backgrounds and are of the same prior academic ability. Interestingly, however, there is no clear difference between boys and girls in their academic drive. On the other hand, although there are sizeable raw socio-economic gaps in teenagers' ambitions (in favour of students from richer backgrounds), these are to a large extent explained by differences in prior academic achievement and differences in the school/local community where they have grown up. Conversely, the socio-economic gap in drive remains after the addition of our rich set of controls.

Importantly, drive and ambition are found to be strongly related to performance in GCSEs; a 15year-old pupil who plans to apply to study at Oxford/Cambridge and is amongst the most driven to succeed, scores on average 0.37 standard deviations higher across their GCSEs than a comparable pupil who does not plan to go to university and has only low levels of drive. This is a large effect size, illustrating just how important it is for young people to remain motivated and focused in the build-up to high-stakes exams.

This paper is now structured as follows. In section 2, we discuss the PISA dataset available for England, including the link that has been made to administrative records in the form of the National Pupil Database (NPD). Our empirical methodology then follows in section 3. Results are presented in section 4, with conclusions and suggested directions for future work following in section 5 .

\section{Data and descriptive statistics} Sample design

PISA is an international study of 15 -year-olds' achievement across three subjects (reading, mathematics and science). We use the data from the 2015 cycle. A two-stage sample design was used. Schools were first sampled with probability proportional to size, and then 42 pupils were randomly selected from within each school (OECD 2016). In England, almost every participating pupil is within the same year group (Year 11). A total of 5,194 pupils from 206 schools in England participated in PISA 2015, which reflects official response rates of 92 percent at the school level and 88 percent at the pupil level. ${ }^{4}$ Throughout our analysis we apply the final pupil response and

\footnotetext{
${ }^{4}$ School-level response rates in England were 83 percent before replacement schools were included and 92 percent after their inclusion. This is similar to the response rates achieved in most other countries and is compliant with the standards set by the OECD.
} 
replicate weights to take the complex PISA survey design into account using the 'repest' command (Avvisati and Keslair 2019). This includes the clustering and stratification used in the sample design.

The PISA 2015 sample for England has been linked to the National Pupil Database (NPD), which includes administrative data on pupils' backgrounds along with their performance on national examinations. A successful link has been made between PISA and the NPD for 4,914 pupils (95 percent of the full sample). The NPD link provides us with access to national prior achievement measures, including pupils' Key Stage 2 test scores, and their (future) Key Stage 4 (GCSE) scores. Key Stage 2 tests are taken at the end of primary school (end of Year 6) and Key Stage 4 tests are taken at the end of compulsory secondary school (end of Year 11). Importantly, note that the GCSE examination period is just six months after pupils take the PISA test.

\section{Measures of academic achievement}

GCSEs refer to England's school leaving qualifications and are based upon a set of examinations taken at the end of Year 11, when young people are aged 15/16. They are high-stakes for both schools and pupils. Schools are ranked nationally depending upon the performance (and progress) made by pupils, with the information made publicly available. For young people, GCSEs determine further labour market and educational opportunities (Moulton et al. 2018), including post-16 pathways $^{5}$, subject choices at A-Level (the examination taken at 18 which determines access to university), access to university and long-run labour market outcomes. Moreover, as GCSE grades will often be taken into account by elite universities when allocating university places, strong performance in these examinations for an ambitious, driven young person is vital.

In each subject, pupils in this cohort received one of eight grades (between $A^{*}$ and $U$ ) for each secondary school subject they take. ${ }^{6}$ The primary outcome measure used in this paper is young people's total capped GCSE points score across their best eight subjects. A histogram illustrating the distribution of this variable as well as the distribution by university application plans can be found in Appendix Figure A2. This is a standard summary achievement metric widely used in analysis of educational achievement data in England, capturing performance across a wide range of subjects (though with greater weight given to the core subjects of English, science and mathematics). Throughout our analysis, this variable has been standardised to mean zero and

\footnotetext{
${ }^{5}$ For Maths and English GCSE, resitting is compulsory for those who do not achieve a pass (grade 4).

${ }^{6}$ This cohort were the last to take GCSEs before they were reformed, with results now reported using a 1 to 9 scale.
} 
standard deviation one, meaning estimates from our model can be interpreted in terms of an effect size. The histogram in panel (a) of Appendix Figure A2 shows a normal distribution of this variable. To test the robustness of our results, in Appendix Table A2 we present alternative estimates focusing upon GCSE mathematics grades as the outcome.

The PISA-NPD database also includes two sources of information about young people's prior academic achievement. The first is the scores they received as 11-year-olds at the end of primary school in their national reading and mathematics exams (Key Stage 2 exams). The second is their scores on the PISA reading, science and mathematics test taken just six months before their GCSEs. Previous research has shown the correlation between PISA scores and GCSE grades to be high ( $r=0.78$ in the case of mathematics, Carroll and Benton (2018)) and hence a high-quality measure for young people's academic abilities before the build-up to their GCSE examinations. In our analysis, we control for both of these measures: PISA scores across all three subjects plus Key Stage 2 scores in both reading and mathematics.

\section{Measurement of socio-economic status}

As part of the PISA study, participating pupils also complete a background questionnaire. This includes information about mothers and fathers' education, occupation and household possessions. The information provided by participating pupils is then converted by the survey organisers into the continuous Economic, Social and Cultural Status (ESCS) scale via a principal components analysis (OECD 2016). Within England, we have divided this scale into five quintiles, with the top and bottom $20 \%$ of the ESCS population defined as "high" and "low" socioeconomic status respectively. From the NPD, we also know whether or not the young person has ever been eligible for Free School Meals, which are only available to disadvantaged individuals and is a commonly used measure of socioeconomic status (Ilie, Sutherland, and Vignoles 2017).

\section{Ambitious educational plans}

Although the vast majority of questions asked in the PISA background questionnaire are common across all participating nations, each country has the opportunity to add up to five minutes' worth of additional national questions. This opportunity was taken up by England in 2015, with pupils first asked:

'How likely do you think it is that you will ever apply to go to university to do a degree?' 
The options from which they could choose were: 'very likely', 'fairly likely', 'not very likely', 'not at all likely', 'don't know'.

Pupils who selected the 'not very likely', 'not at all likely', or 'don't know' option did not answer any further questions in this module. For those who ticked either the 'very likely' or 'fairly likely' option, they were then asked:

\section{'Can you name up to three universities to which you think you might apply?'}

Note that Year 11 pupils' responses to this question were captured via an open-text field; pupils could provide any response and were not constrained to a limited set of options. Quaglia and Cobb (1996, p. 130), define aspirations as young people's “ability to identify and set goals for the future, while being inspired in the present to work towards those goals". Of the 4,914 pupils for whom we have NPD data, 2,678 individuals provided an answer for their top-choice university, 899 individuals left this question blank, and 1,337 individuals did not see this question because they were 'not very likely', 'not at all likely', 'don't know' or did not respond to the initial question about their likelihood of applying to university. If all of the pupils who provided an answer transition to $\mathrm{HE}$, this would give a university participation rate of nearly 55 percent. As a point of comparison, the Higher Education Initial Participation Rate (HEIPR) ${ }^{7}$ in 2015 was 49 percent (Department for Education 2017b).

Throughout this paper we focus upon the first of the three universities named, under the assumption that this was their first or most likely choice. Using their answers, we define as 'ambitious' those who plan to attend a high-ranking university - defined as Oxford or Cambridge ("Oxbridge). ${ }^{8}$ The five most popular universities listed by pupils in England as their top choice university were: Oxford (11\%), Cambridge (8\%), Manchester (5\%), Birmingham (4\%), and Leeds $(4 \%) \cdot{ }^{9}$

\footnotetext{
${ }^{7}$ The HEIPR is an estimate of the likelihood a young person has of entering university based on current participation rates. It is the sum of participation rates from for each age 17 to 30 inclusive. In order to be included in the HEIPR, an individual must live in England, enter higher education for the first time, attend a UK higher education institution or English, Welsh and Scottish further education college, and stay in higher education for at least six months (Department for Education 2017b).

${ }^{8}$ In the Appendix we conduct the same analysis defining an elite university as any Russell Group institution, which has been done in previous work (e.g. Jerrim, Chmielewski, and Parker (2015)). The Russell Group is an association of 24 research intensive universities, which are considered prestigious ("Russell Group | About" n.d.). We also include elite universities from the US (e.g. Ivy League universities) in this category and it does not change our overall results.

${ }^{9}$ See the Appendix Table A6 for a complete list of all universities entered and their corresponding frequencies.
} 
Table 1 presents descriptive statistics for the entire sample, including those who named their top university as Oxford or Cambridge (column 1), a Russell Group (i.e. high status) institution (column 2), another institution (column 3), those who intended to go to university but left the institution name blank (column 4) and finally those who stated they did not intend to go to university (column 5). Those who intend to apply to a high-status university achieve higher Key Stage 2, PISA mathematics and GCSE total point scores than their peers who do not plan to go to university. The differences in GCSE total points by university application plan may be seen in panel (b) of Appendix Figure A2. This clearly shows that GCSE performance increases as university application plans become more ambitious. This is encouraging, since it demonstrates the 'ambitious' plans question is correlated with young people's likeliness to actually attend university and thus does contain useful information. On the other hand, young people who said they were likely to attend university, but did not name a particular institution, are more likely to be eligible for Free School Meals, come from a poorer background (as measured by the ESCS scale) and be boys. Similarly, socioeconomic status is also a potentially important determinant of ambitious university plans. Pupils from the top quintile of the ESCS scale are 5.5 percentage points more likely to list Oxbridge as their first-choice university than their peers from the bottom quintile, i.e. the most disadvantaged background. For Russell Group universities, there is a 15.5. percentage point difference.

\section{$<<$ Table $1>>$}

Table 1 also highlights the gender gap in ambitious university plans. Girls only make up 46\% of those who plan to apply to Oxbridge. Figure 1 shows that this gap not only holds at the mean, but also across the ability distribution. Boys are more likely than girls to name Oxbridge as their top university irrespective of their performance on PISA. The difference is largest for pupils who are low achievers on PISA 2015, but holds for middle and high achievers as well.

\section{$<<$ Figure $1>>$}

\section{Measurement of drive}

As part of the PISA background questionnaire, teenagers were asked to respond to a battery of five questions designed to capture their academic motivation. Responses were provided using a four-point Likert scale (strongly disagree to strongly agree), with the statements as follows:

1. I want top grades in most or all of my courses

2. I want to be able to select from among the best opportunities available when I graduate

3. I want to be the best, whatever I do 
4. I see myself as an ambitious person

5. I want to be one of the best students in my class

The survey organisers have converted young people's responses to these questions into a scale. This has then been standardised to mean zero and standard deviation one within England throughout our analysis. Our analysis investigating the link between drive and performance upon GCSE examinations is based upon this variable, with our focus being upon those in the top versus bottom drive quartiles.

Table 2 provides some descriptive information about this drive scale, illustrating how it differs between various demographic groups. There are clear raw socio-economic differences in levels of drive. Young people from advantaged backgrounds (the top quintile of the ESCS scale) have above average levels of drive while their disadvantaged peers have below average levels. The difference between these groups is 0.4 standard deviations. Young people from advantaged backgrounds are also much more likely to be at the top of the drive scale (24\% compared to $13 \%$ of their disadvantaged peers). The same is true in terms of academic achievement. High academic achievers, whether defined by their performance on Key Stage 2 tests or PISA, have above average levels of drive while they low achieving peers also have lower levels of drive. This provides descriptive evidence that there is a correlation between drive and academic achievement. In terms of gender, the differences are less pronounced. Girls score slightly higher on average than boys (0.09 standard deviations) and are somewhat less likely to be in the bottom quartile of the drive scale. The drive gap is more pronounced for immigrants versus natives. Immigrants exhibit higher levels of drive and are more likely to be in the top quartile of the drive scale than their British peers.

\section{$<<$ Table $2>>$}

\section{Parental educational investments and support}

The PISA questionnaires include several measures of parental support for their offspring and the investments that they make in their education. Firstly, teenagers are asked about the number of hours they spend in additional instruction (outside of core school hours) per week. Second, relatedly, they are asked whether they currently receive private tutoring in English, science and mathematics. Finally, they are also asked a battery of four questions capturing parental interest, engagement and support in their education (e.g. "My parents support my educational efforts and achievements" and "My parents are interested in my school activities"). Together, such variables provide important additional information about parental engagement and investment in their 
offspring's education, which will to some extent reflect their own ambitions for their children. These variables are used as controls within parts of our analysis (further details are provided in section 3).

\section{Other socio-emotional skills}

As well as measuring young people's drive to succeed, the background questionnaire also included a range of questions designed to measure young people's socio-emotional competencies in other areas. This includes test anxiety (e.g. "Even if I am well prepared for a test I feel very anxious"), self-efficacy (e.g. "How easy do you think it would be to perform this task on your own - describe the role of antibiotics in the treatment of disease"), sense of belonging at school (e.g. "Other students seem to like me") value and enjoyment of teamwork (e.g. "I prefer working as part of a team to working alone") and cooperation with peers (e.g. "I am a good listener"). Quintile dummies based on these scales will be used within parts of our analysis to control for the potential confounding effects of other socio-emotional skills.

\section{Methodology}

Examining gender, socio-economic and immigrant gaps in elite university ambitions and academic drive

The first part of our analysis investigates gender, socio-economic and gender gaps in (a) elite university ambitions and (b) academic drive. With respect to the former, multiple specifications of a linear probability model are estimated, ${ }^{10}$ where we sequentially add further controls. These models are based upon a sub-set of 2,813 pupils who were 'fairly' or 'very' likely to apply to university and provided the name of at least one institution to which they were planning to apply.

$Y_{i j}=\alpha+\beta \cdot$ Gender $_{i j}+\phi . S E S_{i j}+\gamma \cdot \operatorname{Imm}_{i j}+\delta \cdot P I S A_{i j}+\tau \cdot K S 2_{i j}+\sigma \cdot A m b_{i j}+\mu_{j}+\varepsilon_{i}$

Where:

$Y_{i j}=$ Either a binary variable taking the value one if the pupil aspires to attend Oxford or Cambridge (reference group is any other named university) or the academic drive scale (standardised).

$\operatorname{Gender}_{i j}=$ A dummy variable for male.

\footnotetext{
${ }^{10}$ Appendix Tables A4 and A5 present alternative results based upon logistic and multinomial logistic regression modelling instead. The results are broadly similar.
} 
$\operatorname{Imm}_{i j}=\mathrm{A}$ dummy variable, taking a value of 1 for the young person being either first- or secondgeneration immigrant, and zero otherwise.

$S E S_{i j}=$ A set of dummy variables for quintiles of the PISA ESCS index.

$\operatorname{PISA}_{i j}=$ Scores on the PISA science, maths and reading test. ${ }^{11}$

$K S 2_{i j}=$ Key Stage 2 mathematics and English points scores (quintile dummies).

$A m b_{i j}=$ Either a set of dummy variables for quartiles of the academic drive scale (reference is the bottom quartile) and only included in the Oxbridge models or a set of dummy variables for university plans (reference is "not planning to apply") and only included in drive models.

$\mu_{j}=$ School fixed effect.

$\varepsilon_{i}=$ Error term. All estimates account for stratified, clustered sample design via the application of the PISA Balanced-Repeated-Replication (BRR) weights.

The subscript $i$ refers to the pupil in school $j$. We include a missing dummy for all missing values of any control variables.

To begin, in model specifications 1-2, only gender or socio-economic status are included in the model. The estimated $\beta, \phi$ and $\gamma$ coefficients thus provide differences in the probability of young people planning to apply to Oxbridge depending upon their gender or family background. Specification 3 then adds controls for prior achievement in the form of Key Stage 2 and PISA test scores as well as some additional demographics. Our parameters of interest $(\beta, \phi$ and $\gamma)$ now reflect differences in plans to apply to an Oxbridge university amongst young people of the same academic ability. School fixed-effects are added in specification 4. Changes in $\beta, \phi$ and $\gamma$ from specification 4 onwards will hence provide some descriptive evidence as to whether gender, socioeconomic and immigrant differences in elite university ambitions is related to the sorting of pupils into different schools. This could of course reflect the impact of what schools do (e.g. foster high academic ambitions via university outreach programmes), peer-effects, geography or self-section into different school types (e.g. parental school preferences). Regardless, estimates from this fourth specification will inform us about gender, socio-economic and immigrant differences amongst teenagers of the same academic ability who go to the same school. The final model then also

\footnotetext{
${ }^{11}$ We include all 30 plausible values. Our results are robust to alternative specifications (e.g. including only the first plausible value from each domain). This provides the best possible control for teenagers' academic abilities and minimises any attenuation that could occur due to measurement error.
} 
controls for quartiles of the 'drive' scale. ${ }^{12}$ This enables us to examine the relationship between academic drive and ambition, with a positive correlation anticipated.

Despite this evidence being purely correlational, these models will nevertheless help us to build a better understanding of how academic ambition and drive differs between some key demographic groups in England. To test the robustness of these results, Appendix Tables A1 provides alternative estimates where the definition of ambitious educational plans is extended from planning to apply to Oxbridge to planning to apply to any Russell Group university.

\section{The link between drive, ambition and educational achievement}

As discussed at length by Gorard, See, and Davies (2011) establishing a causal link between socioemotional competencies, such as ambition and drive, and subsequent educational outcomes is a challenging task. Almost no experimental evidence exists that has managed to raise teenagers' drive and ambition, and link this to their later educational achievement. ${ }^{13}$ It is difficult to think of a potentially credible instrumental variable, let alone have it (plus all other relevant data) available in a dataset. Similarly, other commonly used quasi-experimental estimators, such as regression discontinuity designs and difference-in-difference cannot be applied to this problem (there is no running variable or any policy-variation to exploit). Consequently, like most existing work in this area, evidence of causality will depend upon the extent that the "selection-upon-observables" assumption holds. This, in turn, depends upon our understanding of the selection mechanism and whether such measures are available within our data.

It is hence important that we consider why some teenagers are more ambitious and driven than others (i.e. the "selection mechanism"). Perhaps the most obvious factor is prior academic achievement; young people who have previously done well at schools will be more likely to be determined to do so again, and to set themselves the goal of attending an elite university. Having robust, high-quality prior academic achievement measures is hence a key prerequisite.

\footnotetext{
12 As a robustness check we run these models using the continuous drive scale. This requires mean imputation for the 153 individuals missing the drive scale. Nevertheless, the results are very similar and therefore not reported here. ${ }^{13}$ We believe this is one of the few ways to generate evidence on the link between drive/ambition and achievement, which can account for unobservables. Specifically, one could use the initial random assignment in a randomised controlled trial that successfully raised drive/ambition as an instrumental variable to generate a local average treatment effect for the link between drive/ambition and achievement. To our knowledge, no such experiment or analysis has ever been conducted.
} 
A second key factor is family background. Young people with highly educated, affluent parents in prestigious jobs may be more likely to be driven to succeed and be ambitious themselves. Parents who are ambitious for their offspring may also make additional educational investments (e.g. pay for private tutoring, help with homework) and take more of an active interest in their child's education. This could also then potentially confound the link between young people's drive/ambition and their performance in high-stakes examinations. Similarly, it is well-known that immigrants in a country tend to have high levels of motivation to succeed (Schleicher 2006). Being able to control for such background characteristics is therefore also likely to be vital.

One should also not overlook the potential role of the school young people attend, their peergroup and the characteristics of the area in which they live. Schools with a strong academic ethos may place great emphasis upon motivating their pupils and encourage them to make lofty education plans. At the same time, having ambitious and competitive peers may increase a young person's motivation and drive. On the other hand, if a teenager lives in an area with limited future employment opportunities - or where there are many out-of-work and unmotivated adults - then they may well become less ambitious and driven themselves.

Finally, there may be other socio-emotional or psychological traits that could be linked to drive, ambition and educational achievement. Take, for instance, test anxiety. Ambitious and driven young people could be more stressed about taking high-stakes exams, which then has an impact upon how they perform (either for better - anxiety leading to them doing more revision - or for worse - the stress meaning they cannot function to maximum capacity in an examination setting). Alternatively, individuals with higher levels of self-confidence may also be more ambitious and more driven, which may confound the relationship with future academic achievement. Hence the ability to account for other potentially important socio-emotional skills is also likely to increase our chances of identifying a causal relationship.

The empirical methodology we hence use to investigate the link between ambition, drive and academic achievement is based upon a set of education production functions. These are estimated using OLS regression and controls, as far as possible, for the key potential confounders discussed above. These models are of the form:

$G_{C S E_{i j}}=\alpha+\beta$. ApplicationPlan $_{i j}+\phi \cdot X_{i j}+\delta \cdot P_{I S A_{i j}}+\tau \cdot K S 2_{i j}+\sigma \cdot$ Drive $_{i j}+\mu_{j}+e_{i j}$ 
Where:

$\operatorname{GCSE}_{i j}=$ The measure of academic achievement, GCSE total points (standardised).

ApplicationPlan $_{i j}=\mathrm{A}$ categorical variable with the possible responses to the first-choice university question ('planning to apply, but did not name a university', 'other (non-elite) university', 'Russell Group', and 'Oxbridge' relative to 'not planning to attend university'). The reference category is 'not planning to apply'.

$X_{i j}=$ is a vector of individual characteristics including gender, whether or not the pupil is an immigrant, and whether they are FSM eligible.

PISA $_{i j}=$ Scores on the PISA science, maths and reading test. ${ }^{14}$

$K S 2_{i j}=$ Key Stage 2 mathematics and English points scores (quintile dummies).

Drive $_{i j}=\mathrm{A}$ set of dummy variables for quartiles of the academic drive scale (reference is the bottom quartile).

$e_{i j}=$ Error term. The clustering of pupils within schools, as well as the stratification and survey weighting used in the PISA sample design, is accounted for via the application of the final student and Balanced-Repeated-Replication weights. This is done via the Stata 'repest' package developed by Avvisati and Keslair (2019). See Jerrim et al. (2017)for further details.

A number of features of this model are worthy of further discussion. First, it includes a very rich set of controls for prior achievement. Following standard practise in the economics of education literature (Koedel, Mihaly, and Rockoff 2015), we assume that these capture accumulated human capital up until six months before young people sit their GCSE exams (the point when the PISA survey was conducted and when our measures of drive and ambition are collected). Hence these value-added models will capture how drive and ambition are related to educational progress over a short (yet critical) time horizon.

Second, the model includes school fixed-effects. This is made possible by the PISA sampling methodology which, as described, samples a large number of schools (206) and pupils within schools (42 per school). These will not only help to pick up the impact of school culture and quality, but also the role of school peers in fostering young people's ambition and drive. Similarly, these will partially capture local neighbourhood factors (e.g. the local labour market) as well as factors linked to parental school choice (e.g. parental ambition for their child, including

\footnotetext{
${ }^{14}$ We include all 30 plausible values. Our results are robust to alternative specifications (e.g. including only the first plausible value from each domain). This provides the best possible control for teenagers' academic abilities and minimises any attenuation that could occur due to measurement error.
} 
preferences for a school with a strong academic track record). Hence, by focusing upon withinschool variation only, we will control for several potential confounders of the link between drive, ambition and achievement.

Finally, the model also includes an array of factors linked to parental investments in their offspring's education and engagement in their schooling. This includes investment in private tutors and help with their child's homework. Together, this helps to proxy the role of parents in developing their offspring's skills in the six-months prior to the GCSE exams. Likewise, a set of other socio-emotional competencies (test anxiety, sense of belonging at school, self-efficacy, enjoyment of cooperation, value of cooperation) have also been controlled. It is anticipated that their inclusion will help to rule out the possibility that the estimated association between drive, ambition and GCSE grades is not merely masking the influence of other socio-emotional skills.

Estimates from our final model specification will hence illustrate differences in GCSE grades between 15-year-olds with different levels of ambition and drive, who come from the same demographic background, attend the same school, are of similar academic ability six months before the exams, have parents who are similarly engaged (and make similar investments) in their education, and who are otherwise similar across a range of other socio-emotional traits. There could, of course, still be some factor omitted from the model which could confound the link between drive, ambition and GCSE achievement. One example could be, for instance, genetics, if genetic disposition to ambition and educational achievement are linked. However, we believe it is likely that the rich set of controls included within the model should soak up the vast majority of any such residual confounding. Hence, although identification of causal effects continues to rest upon the untestable selection upon observables assumption, we nevertheless believe that in this situation this assumption is credible. Therefore, although we cannot rule out the possibility of unobserved confounders, we nevertheless believe our results are likely to get closer to estimating causal effects than most of the existing literature (where the selection of controls included in models are much sparser and, in terms of prior achievement, of lower quality).

\section{Results}

\section{Gender, socio-economic and immigrant differences in ambitious university plans}

Table 3 illustrates gender, socio-economic and immigrant differences in 15-year-olds plans to apply to Oxford or Cambridge. All estimates refer to percentage point differences between groups, with a total of $9.6 \%$ of all 15 -year-olds in England indicating that they intend to submit an Oxbridge application. 
Starting with the results for gender, we find robust evidence that boys have more ambitious university plans than girls. In the unconditional model specification, teenage boys are nine percentage points more likely to plan to apply to Oxford or Cambridge than girls. This substantial difference remains intact after we control for demographic background, multiple measures of prior achievement and school fixed-effects. We also add an additional control for career plans, based upon the occupation young people said they expected to hold at age 30. This does not change the results. Appendix Table A1 illustrates that a similar result holds even when we extend our definition of "ambitious plans" from just Oxbridge to all 24 Russell Group universities. There is hence clear evidence that 15-year-old boys hold more ambitious plans than girls.

A similar finding emerges with respect to immigrant status; first- and second-generation immigrants hold much more ambitious academic plans than young people of British heritage. There is an unconditional difference of 14 percentage points, which continues to be observed even after rich measures of prior achievement have been controlled. Indeed, the inclusion of school fixed-effects actually increases the difference between immigrants and natives slightly. Again, a similar result emerges in Appendix Table A1, where the outcome of interest has been broadened to include plans to apply to any of the Russell Group universities. First- and second-generation immigrants are hence much more academically ambitious than their peers of British heritage, even when they are otherwise from a similar background, of similar academic ability, and attend the same school.

Evidence with respect to socio-economic status is more mixed. Teenagers from the wealthiest quintile are 5.5 percentage points more likely to plan to apply to Oxbridge than their peers from the poorest quintile. However, this difference is almost entirely explained by differences in prior academic ability; once PISA and Key Stage 2 scores have been controlled, the socio-economic gap falls to 1.8 percentage points and is no longer statistically significant at conventional thresholds. The inclusion of school fixed-effects does not alter this result. Appendix Table A1 suggests a similar pattern emerges for plans to apply to Russell Group universities, with around half the socioeconomic gap explained by Key Stage 2 and PISA test scores. Yet the remaining socio-economic gap is more substantial (between six and eight percentage points depending upon the precise model specification), though on the boundary of statistical significance at the five percent level. 
In summary, Table 3 and Appendix Table A1 provides clear and consistent evidence with respect to gender and immigrant differences in ambitious university plans. Boys are much more likely to intend to apply to an elite university than girls, while those from an immigrant background are more ambitious than British natives. Evidence with respect to socio-economic differences is more mixed; although teenagers from wealthy backgrounds are more academically ambitious, this is to a large extent driven by their higher levels of prior academic achievement. ${ }^{15}$

\section{Gender, socio-economic and immigrant differences in academic drive}

We delve further into the raw differences in drive between demographic groups in Table 4. These are results from our regression models where academic drive is the outcome variable. As the outcome has been standardised, all estimates can be interpreted as effect sizes.

\section{$<<$ Table $4>>$}

Table 4 shows clear and robust socio-economic differences in academic drive that cannot be explained by prior academic achievement. While the magnitude of this effect decreases from column 2 to column 5, it remains relatively large and statistically significant. An individual at the top of the ESCS scale has 0.31 standard deviations higher drive than a peer in the bottom of the scale even if they have the same PISA and Key Stage 2 performance and attend the same school (column 5). Interestingly, there is no clear difference between boys and girls in their academic drive, despite the observed differences in ambition.

These results also show that an individual who lists Oxbridge as their first-choice university has 0.7 standard deviations higher drive than a peer who does not plan to go to university, conditional on prior attainment, socio-economic status, gender, future career plans, and school attended. This shows a robust relationship between academic drive and ambitious plans for the future.

\section{Ambitious plans and GCSE outcomes}

Table 5 presents results from our regression models, illustrating how our covariates of interest (plans to apply to university and quartiles of the academic drive scale) vary with different sets of controls. As the outcome (GCSE total points score) has been standardised, all estimates can be interpreted as effect sizes.

\section{$<<$ Table $5>>$}

\footnotetext{
${ }^{15}$ Note that there could be merit in exploring the interaction between gender, ethnicity and socio-economic status and these socio-economic factors. However, sample size restrictions essentially rule this out in our models.
} 
There is clearly a large unconditional association between academic ambition, determination to succeed and performance in GCSE examinations (column 1). Teenagers who plan to apply to either Oxford or Cambridge achieve GCSE grades 0.65 standard deviations higher than those who plan to go to university but did not name a precise institution and 1.21 standard deviations higher than those who do not plan to go to university at all. Similarly, there is a 0.58 standard deviation gap between young people who are driven to succeed (top quartile) and those who are not (bottom quartile) (column 2).

A substantial part of these unconditional associations is due to differences in prior academic ability. Once we move to our basic value-added model specification (column 3) the effect sizes are reduced dramatically. Yet, in terms of absolute magnitude, they remain substantial. Teenagers planning to apply to Oxbridge make 0.3 standard deviations more academic progress in the final six months leading up to GCSEs than their peers who are not planning to go to university (and approximately 0.1 standard deviations more than those who plan to apply to a higher education institution outside of the Russell Group). At the same time, young people in the top quartile for academic drive make 0.16 standard deviations more progress over their peers in the bottom quartile (over and above the role of their future academic ambitions). Given the rich prior achievement controls within our model, and the relatively short time horizon being investigated (six months) differences of such magnitude should be considered large.

Some of this remaining difference in progress could of course be due to thus far uncontrolled confounders. One such example is school quality. School fixed-effects are therefore added to the model in column 4, so that we now focus upon within-school variation only. This leads to a relatively small further decline in the parameters of interest, with differences in academic progress associated with our covariates of interest remaining substantial. For instance, an academically driven pupil (top quartile) continues to make 0.17 standard deviations more progress in the sixmonths prior to GCSEs than an unmotivated pupil (bottom quartile), even when they are of the same prior academic ability, attend the same school and are from the same demographic background.

The final column then illustrates how our results change once measures of other socioemotional/non-cognitive skills are controlled (column 5). Again, the change in the coefficients of interest compared to previous specifications are relatively minor. Academic ambition and drive continue to be strongly associated with academic progress in the period leading up to GCSEs; a 
difference of around 0.37 standard deviations between teenagers in the top quartile for academic drive and who plans to apply to an Oxbridge university and teenagers in the bottom drive quartile who intends to apply to a lower-status higher education institution. Individuals in the third quartile of the drive variable still make 0.08 standard deviations more progress than their peers in the bottom quartile, indicating that it is not just about having very high levels of drive. We also explore the role of parental investments and engagement in their child's schooling (Appendix Table A3) and find that the inclusion of these variables does not change the results.

To test the robustness of these findings, Appendix Table A2 investigates GCSE mathematics grades as an alternative outcome. Similar findings continue to hold. There remains a non-trivial difference in academic progress between ambitious, driven teenagers and those who are unmotivated and without an ambitious academic goal. Together, these findings point towards the importance of young people remaining driven and ambitious during their final year at secondary school. Remaining determined to succeed, and the ability to navigate growing distractions at this age, is likely to be key for strong performance in important high-stakes exams.

\section{Conclusion}

Raising educational achievement amongst young people is a key goal of parents, schools, teachers and public policymakers across the world. While these groups play a critical role in skill development, young people must also be motivated and willing to work hard to maximise their educational achievements. Indeed studies (e.g. Chowdry, Crawford, and Goodman (2011)) have demonstrated a link between young people's attitudes and their academic outcomes, even once prior attainment is included. The build-up to important, high-stakes national examinations is likely to be a particularly important time in this respect, with hard-work and focus one of the keys to success. Academic ambition and being driven to succeed are hence likely to be important socioemotional skills that potentially have a major impact upon teenagers' educational outcomes and, consequently, the opportunities available to them in the future.

Yet, despite the importance of this issue, research into the relationship between academic ambition, drive and achievement is relatively limited (Hilmer and Hilmer 2012). Most research that does exist includes a relatively limited set of controls, is not nationally representative and/or focuses upon performance in low-stakes tests (Hattie 2009). There is, on the other hand, no existing evidence on the role played by academic drive and ambition in the build-up to high-stakes examinations (when such factors are likely to take on particular importance). 
This paper has made this contribution to the existing evidence base. Using PISA data linked to the National Pupil Database (NPD) in England, we examine how academic drive and ambitions are related to the progress teenagers make during their final six-months at secondary school. Importantly, these data contain a very rich set of statistical controls (particularly for prior achievement and school factors) enabling us to account for many of the likely sources of potential confounding. Our results illustrate how young people's academic drive and ambition have a large impact upon how they perform in their GCSEs, over and above their prior achievement, family background, school attended, educational investments made by their parents and a range of other socio-emotional skills. Specifically, a teenager who is academically driven (top quartile of the academic drive scale) and ambitious (plans to apply to Oxford or Cambridge university) achieves a total GCSE points score around 0.37 standard deviations higher than their peers who are unmotivated (bottom quartile of the drive scale) and academically unambitious (do not plan to go to university). Importantly, it is not only the individuals with the most ambition or highest level of drive who benefit from these traits. Together, this suggests that policies and initiatives to raise academic ambition and drive - and keeping pupils focused upon their studies as in build-up to high-stakes examinations - may lead to appreciable improvements in young people's GCSE performance.

Our results also highlight both socio-economic and gender gaps in the possession of these socioemotional skills. The fact that the gender gap in ambition remains robust to the inclusion of socioeconomic status, prior attainment, and school fixed effects raises questions about why high attaining girls are uncomfortable making or expressing ambitious university plans. Interestingly, there are no robust gender differences on the drive scale. Perhaps the nature of stating an explicit, ambitious goal, i.e. wanting to attend Oxbridge, is more challenging for girls than describing themselves as highly motivated. While we cannot yet follow the actual application behaviours of the individuals in this dataset, educators should be aware of this gender gap and monitor how it plays out in the school-to-work transition. Existing empirical evidence in the UK shows that women are significantly more likely than men to attend university (Crawford and Greaves 2015). However once prior attainment is accounted for, the female advantage in HE attendance becomes very small, and conversely, when it comes to elite universities, men are more likely to attend than women with the same prior attainment. Relatedly, Campbell et al. (2020) show that among university students with the same academic achievement at high school, males and females enrol in university courses with similar academic requirements, but men are more likely to enrol in 
courses that are offer higher returns in the labour market. Both findings hint at some potential role for ambition.

Meanwhile, our findings point to a socio-economic gap in drive (though not ambition), which also remains after the inclusion of our rich set of controls. The evidence seems to suggest that students from poorer backgrounds are capable of making ambitious choices, but may lack the drive to convert them into reality through improving their school test scores. These findings are aligned with the well-established literature which finds large SES gaps in university attendance, typically driven by prior attainment (Chowdry et al. 2013).

There are, of course, limitations to this work and clear areas where future research is needed. The most prominent example is our reliance upon a selection-upon-observables assumption. Although this is standard practise within this literature, the next important step for this body of work is for experimental evidence to be generated. In particular, large, well-powered randomised controlled trials (RCTs) of interventions designed to raise academic drive and ambition are needed. For those trials with a positive effect, one could use the exogenous variation induced from the random assignment as an instrumental variable to estimate the causal impact of academic drive/ambition upon achievement. Although this may not be easy (and likely expensive) to achieve, such experimental designs would represent a step-change for this literature, and likely to be the only way that evidence will be generated that moves away from a selection-upon-observables assumption.

Despite this limitation, we believe that this paper has added important new evidence on the link between young people's determination to succeed, ambition and academic performance in a highstakes setting. In England, young people, parents, teachers and schools all feel the pressure of the GCSE exams. The results are used for accountability purposes, to publicly rank and compare schools and can feed into evaluations of teachers' performance (Atkinson et al. 2009). They also have important consequences for the individual. Those teenagers who keep their eye on the prize, and who remain motivated to succeed, displaying a mastery-oriented mindset (Elliot and Dweck 1983), have a better chance of getting their reward. Those that do not will be more likely to fail. Helping young people to understand that they are to some extent masters of their own destiny is hence critical as they enter the home stretch towards these important exams. 


\section{References}

Almlund, Mathilde, Angela Lee Duckworth, James Heckman, and Tim Kautz. 2011. "Personality Psychology and Economics." In Handbook of the Economics of Education, edited by Eric A. Hanushek, Stephen Machin, and Ludger Woessmann, 4:1-181. Handbook of The Economics of Education. Elsevier. https://doi.org/10.1016/B978-0-444-53444-6.000018.

Atkinson, Adele, Simon Burgess, Bronwyn Croxson, Paul Gregg, Carol Propper, Helen Slater, and Deborah Wilson. 2009. "Evaluating the Impact of Performance-Related Pay for Teachers in England." Labour Economics 16 (3): 251-61.

Atkinson, J.W. 1964. An Introduction to Motivation. An Introduction to Motivation. Oxford, England: Van Nostrand.

Avvisati, Francesco, and François Keslair. 2019. REPEST: Stata Module to Run Estimations with Weighted Replicate Samples and Plausible Values. Boston College Department of Economics. https://ideas.repec.org/c/boc/bocode/s457918.html.

Barone, Carlo. 2006. "Cultural Capital, Ambition and the Explanation of Inequalities in Learning Outcomes: A Comparative Analysis.” Sociology 40 (6): 1039-58.

Borghans, Lex, Angela Lee Duckworth, James J. Heckman, and Bas ter Weel. 2008. "The Economics and Psychology of Personality Traits.” Journal of Human Resources 43 (4): 972 1059. https://doi.org/10.3368/jhr.43.4.972.

Bowles, Samuel, Herbert Gintis, and Melissa Osborne. 2001. "The Determinants of Earnings: A Behavioral Approach.” Journal of Economic Literature 39 (4): 1137-76.

Campbell, Stuart, Gill Wyness, Lindsey Macmillan, and Richard Murphy. 2020. "Matching in the Dark? Inequalities in Student to Degree Match." Centre for Education Policy and Equalising Opportunities, no. 20-01.

Carneiro, Pedro, Claire Crawford, and Alissa Goodman. 2007. "The Impact of Early Cognitive and Non-Cognitive Skills on Later Outcomes." Centre for the Economics of Education Discussion Papers, no. 92.

Carroll, M, and T Benton. 2018. "The Link between Subject Choices and Achievement at GCSE and Performance in PISA 2015." Cambridge Assessment Research Report. Cambridge, UK: Cambridge Assessment.

Chowdry, Haroon, Claire Crawford, Lorraine Dearden, Alissa Goodman, and Anna Vignoles. 2013. "Widening Participation in Higher Education: Analysis Using Linked Administrative Data: Widening Participation in Higher Education." Journal of the Royal Statistical Society: Series A (Statistics in Society) 176 (2): 431-57. https://doi.org/10.1111/j.1467985X.2012.01043.x.

Chowdry, Haroon, Claire Crawford, and Alissa Goodman. 2011. "The Role of Attitudes and Behaviours in Explaining Socio-Economic Differences in Attainment at Age 16." Longitudinal and Life Course Studies 2 (1): 59-76. https://doi.org/10.14301/llcs.v2i1.141.

Conroy, David E., Andrew J. Elliot, and Todd M. Thrash. 2009. "Achievement Motivation." Handbook of Individual Differences in Social Behavior, 382-99.

Crawford, Claire, and Ellen Greaves. 2015. "Socio-Economic, Ethnic and Gender Differences in HE Participation.” BIS Research Paper, no. 186: 117.

Department for Education. 2017a. "Programme for International Student Assessment (PISA) 2015 Linked to National Pupil Database (NPD)." . 2017b. "Statistics: Participation Rates in Higher Education." Participation Rates in Higher Education for England. September 28, 2017. https://www.gov.uk/government/collections/statistics-on-higher-education-initialparticipation-rates.

Dweck, Carol S., and Ellen L. Leggett. 1988. "A Social-Cognitive Approach to Motivation and Personality.” Psychological Review 95 (2): 256-73. https://doi.org/10.1037/0033295X.95.2.256. 
Elliot, A., and C. S. Dweck. 1983. "Achievement Motivation." In Handbook of Child Psychology: Vol. IV Social and Personality Development, edited by E.M. Hetherington, 643-91. New York: Wiley.

Goldberg, Lewis R. 1990. “An Alternative 'Description of Personality': The Big-Five Factor Structure," 14.

Gorard, Stephen, Beng Huat See, and Peter Davies. 2011. Do Attitudes and Aspirations Matter in Education?: A Review of the Research Evidence. Lambert Academic Publishing.

Hattie, John. 2009. Visible Learning: A Synthesis of over 800 Meta-Analyses Relating to Acbievement. London: Routledge Taylor and Francis Group.

Heckman, James J., Jora Stixrud, and Sergio Urzua. 2006. "The Effects of Cognitive and Noncognitive Abilities on Labor Market Outcomes and Social Behavior." Journal of Labor Economics 24 (3): 411-82.

Hilmer, Michael J., and Christiana E. Hilmer. 2012. "On the Relationship between Student Tastes and Motivations, Higher Education Decisions, and Annual Earnings." Economics of Education Review 31 (1): 66-75. https:// doi.org/10.1016/j.econedurev.2011.09.004.

Ilie, Sonia, Alex Sutherland, and Anna Vignoles. 2017. "Revisiting Free School Meal Eligibility as a Proxy for Pupil Socio-Economic Deprivation." British Educational Research Journal 43 (2): 253-74. https://doi.org/10.1002/berj.3260.

Jerrim, John, Anna K. Chmielewski, and Phil Parker. 2015. "Socioeconomic Inequality in Access to High-Status Colleges: A Cross-Country Comparison." Research in Social Stratification and Mobility 42: 20-32.

Jerrim, John, Luis Alejandro Lopez-Agudo, Oscar D. Marcenaro-Gutierrez, and Nikki Shure. 2017. "What Happens When Econometrics and Psychometrics Collide? An Example Using the PISA Data." Economics of Education Review 61: 51-58.

Koedel, Cory, Kata Mihaly, and Jonah E. Rockoff. 2015. "Value-Added Modeling: A Review." Economics of Education Review 47: 180-95.

Long, James E. 1995. "The Effects of Tastes and Motivation on Individual Income." ILR Review 48 (2): 338-51.

Lynn, R. 1959. "Two Personality Characteristics Related to Academic Achievement." British Journal of Educational Psychology 29 (3): 213-16. https://doi.org/10.1111/j.20448279.1959.tb01501.x.

Moulton, Vanessa, Alice Sullivan, Morag Henderson, and Jake Anders. 2018. "Does What You Study at Age 14-16 Matter for Educational Transitions Post-16?” Oxford Review of Education 44 (1): 94-117.

OECD. 2016. "PISA 2015 Technical Report.” Paris, France: OECD.

Plucker, Jonathan A., and Russell J. Quaglia. 1998. "The Student Aspirations Survey: Assessing Student Effort and Goals.” Educational and Psychological Measurement 58 (2): 252-57. https://doi.org/10.1177/0013164498058002008.

Quaglia, Russell J., and Casey D. Cobb. 1996. "Toward a Theory of Student Aspirations." Journal of Research in Rural Education 12 (3): 127-32.

"Russell Group | About.” n.d. The Russell Group. Accessed April 18, 2019. https://russellgroup.ac.uk/about/.

Schleicher, Andreas. 2006. "Where Immigrant Students Succeed: A Comparative Review of Performance and Engagement in PISA 2003." Intercultural Education 17 (5): 507-16. https://doi.org/10.1080/14675980601063900.

Sirin, Selcuk R. 2005. "Socioeconomic Status and Academic Achievement: A Meta-Analytic Review of Research." Review of Educational Research 75 (3): 417-53. https://doi.org/10.3102/00346543075003417.

Stankov, Lazar, Jihyun Lee, Wenshu Luo, and David J. Hogan. 2012. "Confidence: A Better Predictor of Academic Achievement than Self-Efficacy, Self-Concept and Anxiety?" 
Learning and Individual Differences 22 (6): 747-58.

https://doi.org/10.1016/j.lindif.2012.05.013.

Tuckman, Bruce W. 1999. "A Tripartite Model of Motivation for Achievement:

Attitude/Drive/Strategy." In Annual Meeting of the American Psychological Association, Boston, $M A$.

Valentine, Jeffrey C., David L. DuBois, and Harris Cooper. 2004. "The Relation Between SelfBeliefs and Academic Achievement: A Meta-Analytic Review." Educational Psychologist 39 (2): 111-33. https://doi.org/10.1207/s15326985ep3902_3.

Wong, Maria Meiha, and Mihaly Csikszentmihalyi. 1991. "Motivation and Academic Achievement: The Effects of Personality Traits and the Duality of Experience." Journal of Personality 59 (3): 539-74. 
Figure 1. Gender and SES ability gaps in Oxbridge application plans

(a) Gender differences by ability group

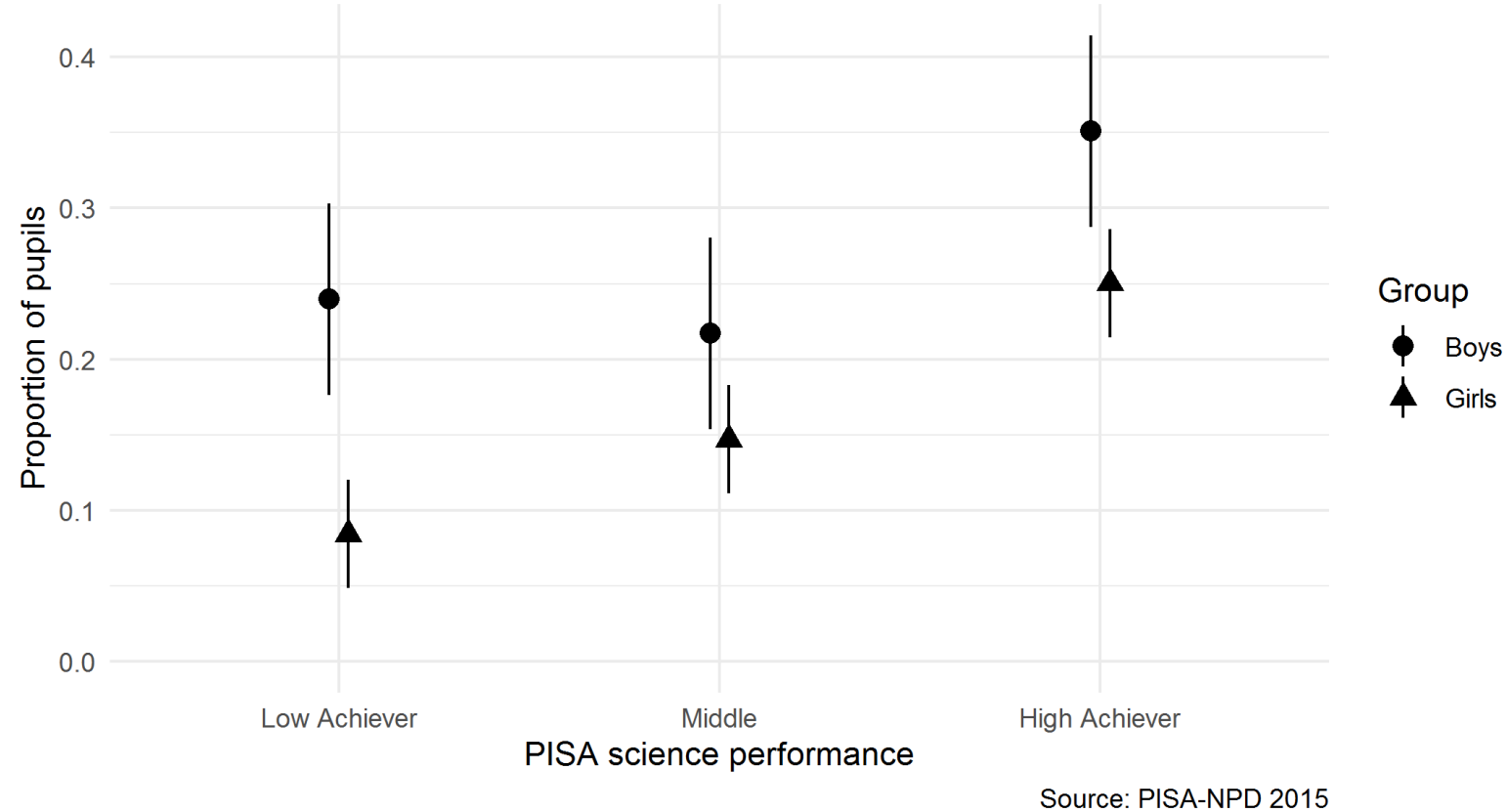

(b) SES differences by ability group



Notes: Panel (a) Total $\mathrm{N}=2,813$. Low achiever group (boys $=146$, girls $=78$; middle achiever group (boys $=1,110$, girls $=875$ ); and high achiever group (boys $=272$, girls $=332$ ). Panel $(\mathrm{b})$ Total $\mathrm{N}=2,813$. Low achiever group (high $\mathrm{SES}=26$, low $\mathrm{SES}=47$ ); middle achiever group (high SES = 570, low SES = 253); and high achiever group (high $\mathrm{SES}=273$, low $\mathrm{SES}=29$ ). Final student weights applied. 
Table 1. Descriptive statistics for young people's educational plans

\begin{tabular}{llllll}
\hline & $(1)$ & $(2)$ & $(3)$ & $(4)$ & $(5)$ \\
& & & & $\begin{array}{l}\text { Left } \\
\text { question } \\
\text { blank }\end{array}$ & $\begin{array}{l}\text { Not } \\
\text { likely to } \\
\text { apply }\end{array}$ \\
\hline Average GCSE total points & 0.517 & 0.445 & 0.087 & -0.132 & -0.687 \\
Average PISA maths score & 548 & 530 & 506 & 484 & 449 \\
Average Key Stage 2 English points & 0.337 & 0.328 & 0.109 & -0.159 & -0.602 \\
Average Key Stage 2 maths points & 0.351 & 0.287 & -0.020 & -0.132 & -0.552 \\
Average drive & 0.530 & 0.214 & 0.150 & -0.135 & -0.413 \\
\% Female & 46.3 & 58.0 & 62.6 & 48.3 & 35.0 \\
\% Immigrant & 16.2 & 8.6 & 8.0 & 10.6 & 5.2 \\
\% Free School Meals & 24.1 & 20.6 & 22.2 & 27.6 & 30.0 \\
\% Private school & 13.7 & 12.7 & 8.2 & 5.2 & 2.4 \\
\% in North & 23.5 & 36.1 & 24.3 & 34.3 & 27.9 \\
\% in Midlands & 25.0 & 24.1 & 34.3 & 25.9 & 35.2 \\
\% in South & 30.8 & 24.0 & 28.6 & 24.1 & 28.4 \\
\% in London & 20.6 & 15.8 & 12.7 & 15.7 & 8.4 \\
Average ESCS index & 0.489 & 0.491 & 0.348 & 0.165 & -0.158 \\
\hline Number of observations & $\mathbf{5 7 6}$ & $\mathbf{1 , 1 5 4}$ & $\mathbf{1 , 0 8 3}$ & $\mathbf{1 , 0 0 8}$ & $\mathbf{1 , 3 7 3}$ \\
\hline
\end{tabular}

Notes: Total N= 5,194. GCSE total points score, Key Stage 2 English and math points scores, drive, and ESCS index are standardised variables. 'Russell Group' does not include Oxford or Cambridge. 'Other' in Column (3) refers to a non-elite university, i.e. a non-Russell Group university. Pupils in Column (4) said they were likely to apply, but did enter the name of their first choice university. Pupils in Column (5) answered that they were unlikely to apply to university, so did not answer any of the university application questions. Final student weights applied. 
Table 2. Descriptive statistics for the link between background characteristics and young people's drive

\begin{tabular}{|c|c|c|c|}
\hline & $\begin{array}{l}\text { Drive } \\
\text { scale }\end{array}$ & $\begin{array}{c}\% \text { bottom } \\
\text { drive quartile }\end{array}$ & $\begin{array}{c}\% \text { top drive } \\
\text { quartile }\end{array}$ \\
\hline \multicolumn{4}{|l|}{ Key Stage 2 total points } \\
\hline Low achiever (KS2 quintile 1) & -0.286 & 24.3 & 12.0 \\
\hline High achiever (KS2 quintile 5) & 0.220 & 14.7 & 27.7 \\
\hline \multicolumn{4}{|l|}{ PISA science scores } \\
\hline Low achiever (PISA quintile 1) & -0.135 & 19.1 & 15.2 \\
\hline High achiever (PISA quintile 5) & 0.209 & 9.6 & 16.5 \\
\hline \multicolumn{4}{|l|}{ Gender } \\
\hline Male & -0.020 & 53.1 & 50.8 \\
\hline Female & -0.011 & 46.9 & 49.2 \\
\hline \multicolumn{4}{|l|}{ Immigrant status } \\
\hline Native & -0.028 & 88.3 & 74.8 \\
\hline Immigrant & 0.105 & 11.7 & 25.2 \\
\hline \multicolumn{4}{|l|}{ School type } \\
\hline State school & -0.018 & 92.6 & 91.9 \\
\hline Private school & 0.012 & 7.4 & 8.1 \\
\hline \multicolumn{4}{|l|}{ Socio-economic status } \\
\hline Low SES (ESCS quintile 1) & -0.215 & 25.9 & 13.1 \\
\hline High SES (ESCS quintile 5) & 0.201 & 15.7 & 24.3 \\
\hline
\end{tabular}


Table 3. Gender and socio-economic differences in Oxbridge application plans

(1)

$0.091^{* * * *}$

(0.022)

Ref: Lowest SES quintile

Highest SES quintile

Immigrant

Ref: Drive bottom quartile

Drive top quartile

Drive third quartile

Drive second quartile
(2)

(3)

$0.078 * * *$

(4)

(5)

(0.022)

$0.080 * * *$

$0.076^{* * *}$

$(0.022)$

(0.022)

0.018

0.027

0.010

$(0.027)$

(0.028)

(0.031)

$0.142 * * *$

$0.156 * * *$

$0.145^{* * *}$

$(0.025) \quad(0.030)$

$0.126^{* * *}$

$0.051^{* *}$

$0.070 * * *$

Career dummies

Key Stage 2 English and maths points PISA plausible values

School fixed effects

\begin{tabular}{l}
- \\
- \\
- \\
- \\
\hline
\end{tabular}

Number of observations 2,813 2,813

$\mathbf{R}^{2}$ 0.013

0.005

0.074

0.170

0.204

Yes

Yes

Yes

Yes

Notes: Sample restricted to 2,813 pupils who said they were likely to apply to university and named at least one institution. All results obtained using ordinary least squares regressions. Estimates refer to percentage point differences (e.g. a value of 0.09 corresponds to 9 percentage points). Standard errors in parentheses.

${ }^{* * *} \mathrm{p}<0.01,{ }^{* *} \mathrm{p}<0.05,{ }^{*} \mathrm{p}<0.1$. All 30 PISA plausible values are included as are all ESCS, Key Stage 2 English and maths, and motivation quartile dummies. Final student weights applied. Clustering and stratification used in the PISA sample design accounted for by the application of the Balanced-Repeated-Replication weights. 
Table 4. Gender and socio-economic differences in academic drive

(1)

$-0.009$

$(0.027)$

Ref: Lowest SES quintile

Highest SES quintile

Immigrant$$
0.416^{* * *}
$$

Ref: Not planning to attend university

Oxbridge

\section{Russell Group}

Other (non-elite) university

Planning to apply, but did not name university
(3)

(4)

(5)

$\begin{array}{lll}0.046 & 0.014 & 0.094 * \\ (0.032) & (0.034) & (0.037)\end{array}$

$0.451 * * *$

$0.310^{* * *}$

(0.055)

(0.051)

$0.364 * * *$

$0.224 * * *$

$0.140^{* * *}$

$(0.042)$

$(0.051)$

$(0.050)$
$0.703 * * *$

$(0.062)$

$0.443^{* * *}$

(0.046)

$0.418^{* * *}$

$0.180^{* * *}$

(0.047)

Career dummies

Key Stage 2 English and maths points PISA plausible values

School fixed effects

Number of observations

$\mathbf{R}^{2}$

0.000

\begin{tabular}{cccc} 
& - & - & Yes \\
& Yes & Yes & Yes \\
& Yes & Yes & Yes \\
& - & Yes & Yes \\
\hline 5,041 & 5,041 & 5,041 & 5,041 \\
0.019 & 0.088 & 0.174 & 0.230
\end{tabular}

Notes: Sample includes data from all 5,041 pupils for whom PISA-NPD linked data (excluding GCSE results) are available. All results obtained using ordinary least squares regression. Standard errors in parentheses. ${ }^{* * *} \mathrm{p}<0.01,{ }^{* *} \mathrm{p}<0.05,{ }^{*} \mathrm{p}<0.1$. All 30 PISA plausible values are included as are all ESCS, and Key Stage 2 English and maths points quintile dummies. The drive scale has been standardised; estimates can therefore be interpreted as effect sizes. Final student weights applied. Clustering and stratification used in the PISA sample design accounted for by the application of the Balanced-Repeated-Replication weights 
Table 5. The association between academic drive, ambition and GCSE total points

\begin{tabular}{|c|c|c|c|c|c|}
\hline & $(1)$ & $(2)$ & (3) & $(4)$ & $(5)$ \\
\hline \multicolumn{6}{|l|}{$\begin{array}{l}\text { Ref: Not planning to attend } \\
\text { university }\end{array}$} \\
\hline \multirow[t]{2}{*}{ Oxbridge } & $1.208^{* * *}$ & & $0.304 * * *$ & $0.240^{* * *}$ & $0.196^{* * *}$ \\
\hline & $(0.065)$ & & $(0.049)$ & $(0.038)$ & $(0.042)$ \\
\hline \multirow[t]{2}{*}{ Russell Group } & $1.132^{* * *}$ & & $0.323^{* * *}$ & $0.245^{* * *}$ & $0.202^{* * *}$ \\
\hline & $(0.052)$ & & $(0.041)$ & $(0.025)$ & $(0.026)$ \\
\hline \multirow[t]{2}{*}{ Other (non-elite) university } & $0.806^{* * *}$ & & $0.196^{* * *}$ & $0.163^{* * *}$ & $0.121 * * *$ \\
\hline & $(0.046)$ & & $(0.037)$ & $(0.027)$ & $(0.027)$ \\
\hline \multirow[t]{2}{*}{$\begin{array}{l}\text { Planning to apply, but did not name } \\
\text { uni }\end{array}$} & $0.555^{* * *}$ & & $0.140^{* * *}$ & $0.138^{* * *}$ & $0.107 * * *$ \\
\hline & $(0.053)$ & & $(0.032)$ & $(0.025)$ & $(0.025)$ \\
\hline \multirow[t]{2}{*}{ Male } & & & $-0.218^{* * *}$ & $-0.211 * * *$ & $-0.221 * * *$ \\
\hline & & & $(0.023)$ & $(0.023)$ & $(0.026)$ \\
\hline \multicolumn{6}{|l|}{ Ref: Lowest SES Quintile } \\
\hline \multirow[t]{2}{*}{ Highest SES Quintile } & & & $0.169 * * *$ & $0.126^{* * *}$ & $0.106^{* * *}$ \\
\hline & & & $(0.043)$ & $(0.030)$ & $(0.030)$ \\
\hline \multirow[t]{2}{*}{ Ever Free School Meals } & & & $-0.130 * * *$ & $-0.118^{* * *}$ & $-0.115^{* * *}$ \\
\hline & & & $(0.029)$ & $(0.021)$ & $(0.020)$ \\
\hline \multirow[t]{2}{*}{ Immigrant } & & & $0.229 * * *$ & 0.051 & 0.038 \\
\hline & & & $(0.036)$ & $(0.063)$ & $(0.063)$ \\
\hline \multicolumn{6}{|l|}{ Ref: Drive bottom quartile } \\
\hline \multirow[t]{2}{*}{ Drive top quartile } & & $0.584 * * *$ & $0.157 * * *$ & $0.168^{* * *}$ & $0.171 * * *$ \\
\hline & & $(0.040)$ & $(0.033)$ & $(0.029)$ & $(0.029)$ \\
\hline \multirow[t]{2}{*}{ Drive third quartile } & & $0.354 * * *$ & $0.083^{* * *}$ & $0.097 * * *$ & $0.084 * * *$ \\
\hline & & $(0.044)$ & $(0.027)$ & $(0.025)$ & $(0.024)$ \\
\hline \multirow[t]{2}{*}{ Drive second quartile } & & $0.086^{*}$ & 0.008 & 0.040 & 0.031 \\
\hline & & $(0.047)$ & $(0.030)$ & $(0.029)$ & $(0.026)$ \\
\hline Additional socio-emotional skills & - & - & - & - & Yes \\
\hline Career dummies & - & - & - & - & Yes \\
\hline $\begin{array}{l}\text { Key Stage } 2 \text { English and maths } \\
\text { points }\end{array}$ & - & - & Yes & Yes & Yes \\
\hline PISA plausible values & - & - & Yes & Yes & Yes \\
\hline School fixed effects & - & - & - & Yes & Yes \\
\hline Number of observations & 4,914 & 4,914 & 4,914 & 4,914 & 4,914 \\
\hline $\mathbf{R}^{2}$ & 0.202 & 0.058 & 0.618 & 0.729 & 0.736 \\
\hline
\end{tabular}

Notes: Sample includes data from all 4,914 pupils for whom PISA-NPD linked data (including GCSE results) are available. All results obtained using ordinary least squares regression. Standard errors in parentheses. ${ }^{* * *} \mathrm{p}<0.01, * *$ $\mathrm{p}<0.05, * \mathrm{p}<0.1$. All 30 PISA plausible values are included as are all ESCS, Key Stage 2 English and maths points, and motivation quartile dummies. Total GCSE points have been standardised; estimates can therefore be interpreted as effect sizes. Final student weights applied. Clustering and stratification used in the PISA sample design accounted for by the application of the Balanced-Repeated-Replication weights. 
Figure A1. Gender and SES ability gaps in Russell Group application plans

(a) Gender differences by ability group

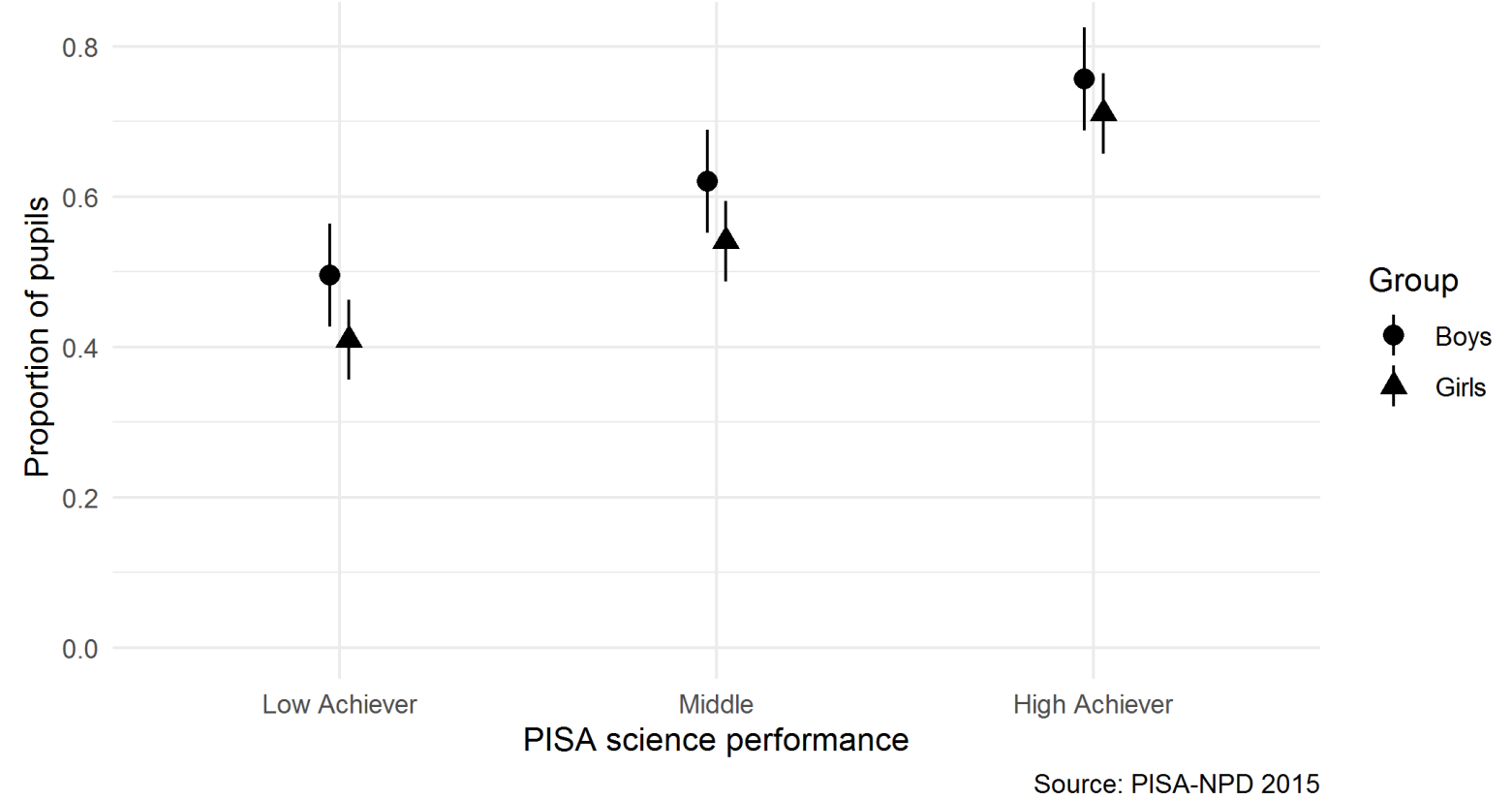

(b) SES differences by ability group



Notes: Panel (a) Total $\mathrm{N}=2,813$. Low achiever group (boys $=146$, girls $=78$; middle achiever group (boys $=1,110$, girls $=875$ ); and high achiever group (boys $=272$, girls $=332$ ). Panel $(b)$ Total $\mathrm{N}=2,813$. Low achiever group (high SES = 26, low SES = 47); middle achiever group (high SES = 570, low SES = 253); and high achiever group (high SES $=273$, low SES $=29$ ). Final student weights applied. 
Figure A2. Histograms of standardised GCSE total points

(a) Distribution of GCSE total points

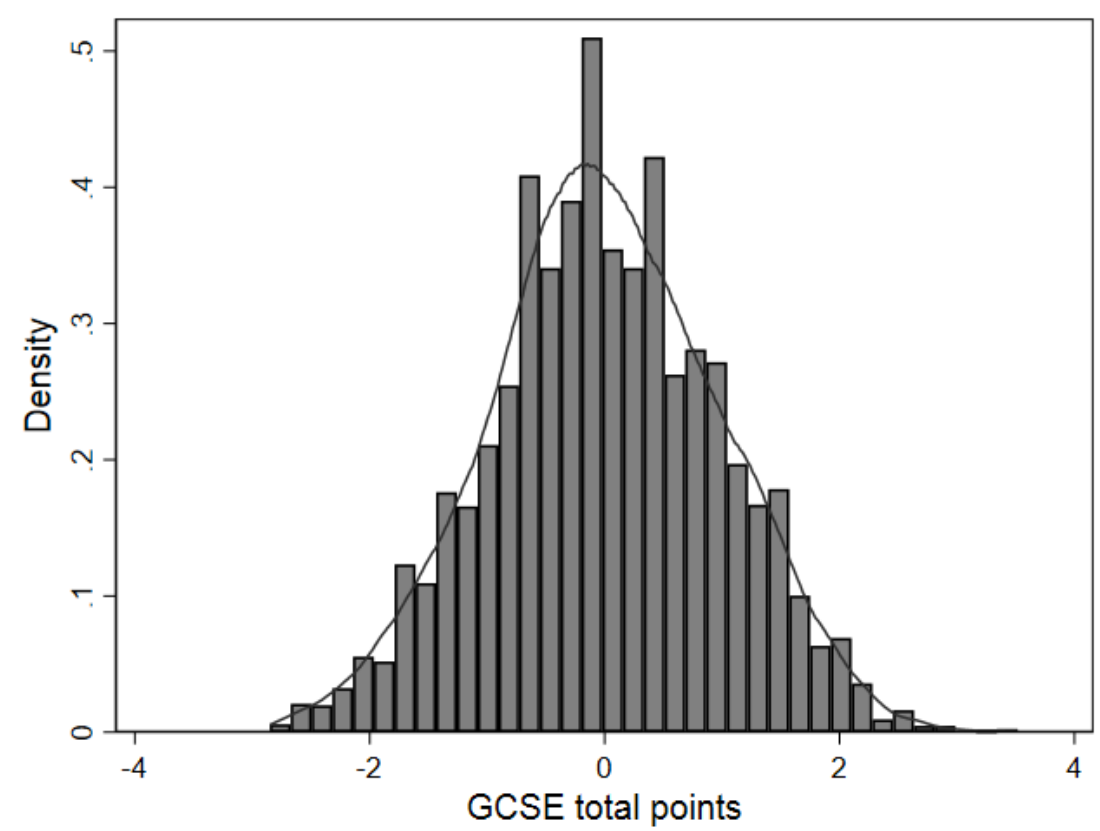

(b) Distributions of GCSE total points by university plan

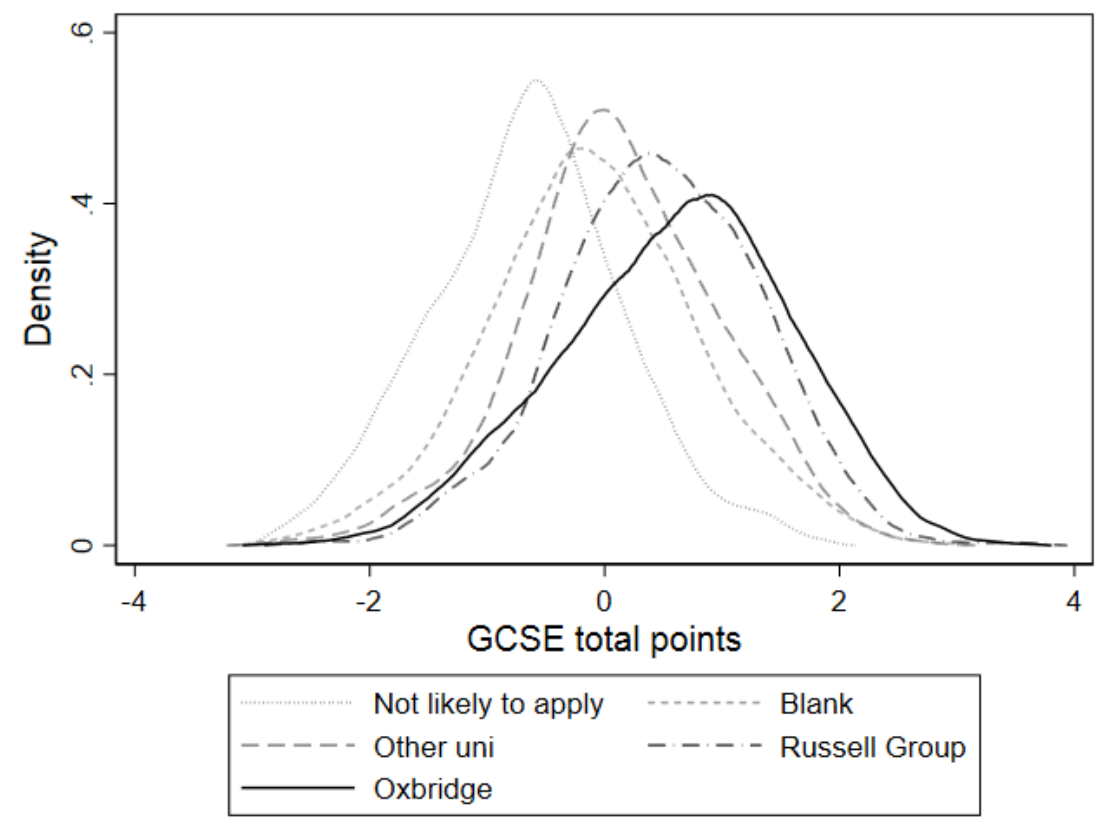

Notes: $\mathrm{N}=4,914$. GCSE total points have been standardised to mean zero, standard deviation one. Kernel density estimates. 
Table A1. Gaps in Russell Group application plans

\begin{tabular}{|c|c|c|c|c|c|}
\hline & $(1)$ & $(2)$ & (3) & $(4)$ & $(5)$ \\
\hline \multirow[t]{2}{*}{ Male } & $0.087^{* * *}$ & & $0.064 * * *$ & $0.070 * * *$ & $0.068^{* * *}$ \\
\hline & $(0.024)$ & & $(0.022)$ & $(0.024)$ & $(0.023)$ \\
\hline \multicolumn{6}{|l|}{ Ref: Lowest SES quintile } \\
\hline \multirow[t]{2}{*}{ Highest SES quintile } & & $0.155^{* * *}$ & $0.081 * *$ & 0.064 & 0.054 \\
\hline & & $(0.037)$ & $(0.041)$ & $(0.047)$ & $(0.045)$ \\
\hline \multirow[t]{2}{*}{ Immigrant } & & & $0.122^{* * *}$ & $0.138^{* * *}$ & $0.114 * *$ \\
\hline & & & $(0.034)$ & $(0.038)$ & $(0.043)$ \\
\hline \multicolumn{6}{|l|}{ Ref: Drive bottom quartile } \\
\hline \multirow[t]{2}{*}{ Drive top quartile } & & & & & $0.113^{* * *}$ \\
\hline & & & & & $(0.035)$ \\
\hline \multirow[t]{2}{*}{ Drive third quartile } & & & & & $0.094^{* * *}$ \\
\hline & & & & & $(0.033)$ \\
\hline \multirow[t]{2}{*}{ Drive second quartile } & & & & & $0.118^{* * *}$ \\
\hline & & & & & $(0.037)$ \\
\hline Career dummies & - & - & - & - & Yes \\
\hline Key Stage 2 English and maths points & - & - & Yes & Yes & Yes \\
\hline PISA plausible values & - & - & Yes & Yes & Yes \\
\hline School fixed effects & - & - & 20 & Yes & Yes \\
\hline Number of observations & 2,813 & 2,813 & 2,813 & 2,813 & 2,813 \\
\hline $\mathbf{R}^{2}$ & 0.008 & 0.019 & 0.078 & 0.219 & 0.251 \\
\hline
\end{tabular}

Notes: Sample restricted to 2,813 pupils who said they were likely to apply to university and named at least one institution. All results obtained using ordinary least squares regressions. Estimates refer to percentage point differences (e.g. a value of 0.09 corresponds to 9 percentage points). Standard errors in parentheses.

${ }^{* * *} \mathrm{p}<0.01, * * \mathrm{p}<0.05, * \mathrm{p}<0.1$. All 30 PISA plausible values are included as are all ESCS, Key Stage 2 English and maths, and motivation quartile dummies. Russell Group includes Oxford and Cambridge. Final student weights applied. Clustering and stratification used in the PISA sample design accounted for by the application of the Balanced-Repeated-Replication weights. 
Table A2. The association between academic drive, ambition and GCSE mathematics points

\begin{tabular}{|c|c|c|c|c|c|}
\hline & $(1)$ & $(2)$ & (3) & (4) & (5) \\
\hline \multicolumn{6}{|l|}{ Ref: Not planning to attend university } \\
\hline \multirow[t]{2}{*}{ Oxbridge } & $0.947 * * *$ & & $0.219^{* * *}$ & $0.164 * * *$ & $0.151^{* * *}$ \\
\hline & $(0.060)$ & & $(0.054)$ & $(0.041)$ & $(0.049)$ \\
\hline \multirow[t]{2}{*}{ Russell Group } & $0.845^{* * *}$ & & $0.214^{* * *}$ & $0.150^{* * *}$ & $0.130^{* * *}$ \\
\hline & $(0.048)$ & & $(0.035)$ & $(0.027)$ & $(0.029)$ \\
\hline \multirow[t]{2}{*}{ Other (non-elite) university } & $0.625^{* * *}$ & & $0.172^{* * *}$ & $0.132^{* * *}$ & $0.118^{* * *}$ \\
\hline & $(0.048)$ & & $(0.043)$ & $(0.026)$ & $(0.026)$ \\
\hline \multirow[t]{2}{*}{ Planning to apply, but did not name uni } & $0.450^{* * *}$ & & $0.129 * * *$ & $0.106^{* * *}$ & $0.100^{* * *}$ \\
\hline & $(0.043)$ & & $(0.029)$ & $(0.028)$ & $(0.028)$ \\
\hline \multirow[t]{2}{*}{ Male } & & & $-0.049 *$ & -0.027 & -0.062 \\
\hline & & & $(0.029)$ & $(0.022)$ & $(0.024)$ \\
\hline \multicolumn{6}{|l|}{ Ref: Lowest SES Quintile } \\
\hline \multirow[t]{2}{*}{ Highest SES Quintile } & & & 0.037 & 0.009 & 0.008 \\
\hline & & & $(0.054)$ & $(0.038)$ & $(0.038)$ \\
\hline \multirow[t]{2}{*}{ Ever Free School Meals } & & & $-0.142^{* * *}$ & $-0.139 * * *$ & $-0.132^{* * *}$ \\
\hline & & & $(0.028)$ & $(0.020)$ & $(0.019)$ \\
\hline \multirow[t]{2}{*}{ Immigrant } & & & $0.262^{* * *}$ & $0.108^{* * *}$ & $0.102 * * *$ \\
\hline & & & $(0.049)$ & $(0.068)$ & $(0.025)$ \\
\hline \multicolumn{6}{|l|}{ Ref: Drive bottom quartile } \\
\hline \multirow[t]{2}{*}{ Drive top quartile } & & $0.445^{* * *}$ & $0.091^{* * *}$ & $0.123^{* * *}$ & $0.121 * * *$ \\
\hline & & $(0.036)$ & $(0.029)$ & $(0.025)$ & $(0.027)$ \\
\hline \multirow[t]{2}{*}{ Drive third quartile } & & $0.263^{* * *}$ & $0.045^{*}$ & $0.056^{*}$ & $0.050^{*}$ \\
\hline & & $(0.042)$ & $(0.027)$ & $(0.029)$ & $(0.028)$ \\
\hline \multirow[t]{2}{*}{ Drive second quartile } & & 0.041 & -0.012 & 0.022 & 0.020 \\
\hline & & $(0.042)$ & $(0.025)$ & $(0.027)$ & $(0.023)$ \\
\hline Additional socio-emotional skills & - & - & - & - & Yes \\
\hline Career dummies & - & - & - & - & Yes \\
\hline Key Stage 2 English and maths points & - & - & Yes & Yes & Yes \\
\hline PISA plausible values & - & - & Yes & Yes & Yes \\
\hline School fixed effects & - & - & Yes & Yes & Yes \\
\hline Number of observations & 4,913 & 4,913 & 4,913 & 4,913 & 4,913 \\
\hline $\mathbf{R}^{2}$ & 0.123 & 0.039 & 0.503 & 0.656 & 0.661 \\
\hline
\end{tabular}

Notes: Sample includes data from all 4,913 pupils for whom PISA-NPD linked data (including total GCSE

Mathematics points) are available. All results obtained using ordinary least squares regression. Standard errors in parentheses. ${ }^{* * *} \mathrm{p}<0.01,{ }^{* *} \mathrm{p}<0.05,{ }^{*} \mathrm{p}<0.1$. All 30 PISA plausible values are included as are all ESCS, Key Stage 2 English and maths points, and motivation quartile dummies. Mathematics GCSE points have been standardised; estimates can therefore be interpreted as effect sizes. Final student weights applied. Clustering and stratification used in the PISA sample design accounted for by the application of the Balanced-Repeated-Replication weights. 
Table A3. Parental investments

\begin{tabular}{|c|c|c|c|}
\hline & $(1)$ & $(2)$ & (3) \\
\hline & $\begin{array}{l}\text { Total GCSE } \\
\text { points }\end{array}$ & $\begin{array}{l}\text { Total GCSE } \\
\text { points }\end{array}$ & $\begin{array}{l}\text { Total GCSE } \\
\text { points }\end{array}$ \\
\hline \multicolumn{4}{|l|}{ Ref: Not planning to attend university } \\
\hline \multirow[t]{2}{*}{ Planning to apply, but did not name uni } & $0.120^{* * *}$ & $0.119^{* * *}$ & $0.102^{* * *}$ \\
\hline & $(0.025)$ & $(0.025)$ & $(0.029)$ \\
\hline \multirow[t]{2}{*}{ Other (non-elite) university } & $0.135^{* * *}$ & $0.134 * * *$ & $0.127^{* * *}$ \\
\hline & $(0.028)$ & $(0.028)$ & $(0.030)$ \\
\hline \multirow[t]{2}{*}{ Russell Group } & $0.216^{* * *}$ & $0.215^{* * *}$ & $0.212^{* * *}$ \\
\hline & $(0.025)$ & $(0.025)$ & $(0.030)$ \\
\hline \multirow[t]{2}{*}{ Oxbridge } & $0.215^{* * *}$ & $0.215^{* * *}$ & $0.199 * * *$ \\
\hline & $(0.039)$ & $(0.038)$ & $(0.047)$ \\
\hline \multirow[t]{2}{*}{ Male } & $-0.208^{* * *}$ & $-0.210^{* * *}$ & $-0.191 * * *$ \\
\hline & $(0.025)$ & $(0.025)$ & $(0.030)$ \\
\hline \multicolumn{4}{|l|}{ Ref: Lowest SES Quintile } \\
\hline \multirow[t]{2}{*}{ Highest SES Quintile } & $0.116^{* * *}$ & $0.113^{* * *}$ & $0.108^{* * *}$ \\
\hline & $(0.031)$ & $(0.032)$ & $(0.033)$ \\
\hline \multirow[t]{2}{*}{ Ever Free School Meals } & $-0.113^{* * *}$ & $-0.113^{* * *}$ & $-0.093 * * *$ \\
\hline & $(0.020)$ & $(0.020)$ & $(0.023)$ \\
\hline \multirow[t]{2}{*}{ Immigrant } & 0.104 & 0.106 & 0.091 \\
\hline & $(0.026)$ & $(0.026)$ & $(0.028)$ \\
\hline \multicolumn{4}{|l|}{ Ref: Drive bottom quartile } \\
\hline \multirow[t]{2}{*}{ Drive top quartile } & $0.184 * * *$ & $0.185^{* * *}$ & $0.169^{* * *}$ \\
\hline & $(0.028)$ & $(0.027)$ & $(0.030)$ \\
\hline \multirow[t]{2}{*}{ Hours of additional instruction per week } & & & 0.000 \\
\hline & & & $(0.001)$ \\
\hline Parental support variables & Yes & Yes & Yes \\
\hline Private tutoring dummies & - & Yes & Yes \\
\hline Career dummies & Yes & Yes & Yes \\
\hline Key Stage 2 English and maths points & Yes & Yes & Yes \\
\hline PISA plausible values & Yes & Yes & Yes \\
\hline School fixed effects & Yes & Yes & Yes \\
\hline Number of observations & 4,914 & 4,914 & 4,133 \\
\hline $\mathbf{R}^{2}$ & 0.733 & 0.734 & 0.730 \\
\hline
\end{tabular}

Notes: Sample includes data from all 4,914 pupils for whom PISA-NPD linked data are available. All results obtained using ordinary least squares regression. Standard errors in parentheses. ${ }^{* * *} \mathrm{p}<0.01,{ }^{* *} \mathrm{p}<0.05,{ }^{*} \mathrm{p}<0.1$. All 30 PISA plausible values are included as are all ESCS, Key Stage 2 English and maths points, and motivation quartile dummies. Total GCSE points have been standardised; estimates can therefore be interpreted as effect sizes. Final student weights applied. Clustering and stratification used in the PISA sample design accounted for by the application of the Balanced-Repeated-Replication weights. 
Table A4. Logistic regressions predicting Oxbridge university plans

\begin{tabular}{lccc}
\hline & $\begin{array}{c}(\mathbf{1}) \\
\text { Oxbridge }\end{array}$ & $\begin{array}{c}(\mathbf{2}) \\
\text { Oxbridge }\end{array}$ & $\begin{array}{c}(\mathbf{3}) \\
\text { Oxbridge }\end{array}$ \\
\hline Male & $1.770^{* * *}$ & & $1.672^{* * *}$ \\
Ref: Lowest SES Quintile & $(0.232)$ & & $(0.251)$ \\
Highest SES Quintile & & $1.404^{*}$ & 1.086 \\
Immigrant & & $(0.243)$ & $(0.221)$ \\
Ref: Drive bottom quartile & & & $2.304^{* * *}$ \\
Drive top quartile & & & $(0.321)$ \\
& - & & $3.120^{* * *}$ \\
Key Stage 2 English and maths points & - & - & $(0.726)$ \\
PISA plausible values & & - & Yes \\
Number of observations & 2,813 & 2,813 & Yes \\
\hline
\end{tabular}

Notes: Sample restricted to 2,813 pupils who said they were likely to apply to university and named at least one institution. All results obtained using logistic regressions. Estimates are odds ratios (e.g. a value greater than one refers to a higher odds). Standard errors in parentheses. ${ }^{* * *} \mathrm{p}<0.01,{ }^{* *} \mathrm{p}<0.05,{ }^{*} \mathrm{p}<0.1$. All 30 PISA plausible values are included as are all ESCS, Key Stage 2 English and maths, and motivation quartile dummies. School fixed effects are not included due to small cell size. Final student weights applied. Clustering and stratification used in the PISA sample design accounted for by the application of the Balanced-Repeated-Replication weights. 
Table A5. Multinomial logistic regression predicting university choice

\begin{tabular}{lcccc}
\hline \multicolumn{2}{c}{ Russell Group } & \multicolumn{2}{c}{ Oxbridge } \\
\hline M1 & OR & SE & OR & SE \\
Male & $1.208^{*}$ & $(0.128)$ & $1.939^{* * *}$ & $(0.298)$ \\
M2 & & & & \\
$\begin{array}{l}\text { Ref: Lowest SES quintile } \\
\text { Highest SES quintile }\end{array}$ & $1.764^{* * *}$ & $(0.291)$ & $1.776^{* * *}$ & $(0.348)$ \\
M3 & & & & \\
$\begin{array}{l}\text { Male } \\
\text { Ref: Lowest SES quintile }\end{array}$ & 1.125 & $(0.112)$ & $1.774^{* * *}$ & $(0.303)$ \\
$\begin{array}{l}\text { Highest SES quintile } \\
\text { Immigrant }\end{array}$ & $1.363^{*}$ & $(0.248)$ & 1.182 & $(0.267)$ \\
$\begin{array}{l}\text { Ref: bottom drive quartile } \\
\text { Top drive quartile }\end{array}$ & $1.294^{*}$ & $(0.191)$ & $2.584^{* * *}$ & $(0.370)$ \\
\hline
\end{tabular}

Notes: $\mathrm{N}=2,813$. Baseline category is 'other university'. M1 and M2 are unconditional models. M3 also includes KS2 math and English quintile dummies and all 30 PISA plausible values. Standard errors in parentheses. ${ }^{* * *} \mathrm{p}<0.01,{ }^{* *} \mathrm{p}<0.05,{ }^{*} \mathrm{p}<0.1$. School fixed effects are not included due to small cell size. Final student weights applied. Clustering and stratification used in the PISA sample design accounted for by the application of the Balanced-Repeated-Replication weights. 
Table A6. First choice universities by frequency

\begin{tabular}{|c|c|c|}
\hline Institution & Frequency & Percent \\
\hline The University of Oxford & 313 & 10.82 \\
\hline The University of Cambridge & 220 & 7.63 \\
\hline The University of Manchester & 138 & 4.77 \\
\hline The University of Birmingham & 122 & 4.22 \\
\hline The University of Leeds & 106 & 3.67 \\
\hline The University of Bath & 93 & 3.2 \\
\hline University of Durham & 66 & 2.27 \\
\hline University College London & 65 & 2.24 \\
\hline The University of Liverpool & 59 & 2.04 \\
\hline Imperial College of Science, Technology & 54 & 1.88 \\
\hline Other answer - Not valid answer & 52 & 1.8 \\
\hline Other Universities in the United States & 50 & 1.75 \\
\hline The University of York & 49 & 1.7 \\
\hline The University of East Anglia & 49 & 1.7 \\
\hline The University of Southampton & 49 & 1.68 \\
\hline The University of Exeter & 48 & 1.67 \\
\hline The University of Bristol & 44 & 1.51 \\
\hline King's College London & 41 & 1.42 \\
\hline Loughborough University & 41 & 1.41 \\
\hline The University of Sheffield & 40 & 1.39 \\
\hline University of Newcastle-upon-Tyne & 40 & 1.37 \\
\hline The University of Edinburgh & 37 & 1.29 \\
\hline Bournemouth University & 37 & 1.28 \\
\hline Other Universities in UK England - Lond & 36 & 1.26 \\
\hline University of Nottingham & 36 & 1.25 \\
\hline The University of Brighton & 35 & 1.2 \\
\hline Other answer - Unsure / Doesn't know & 30 & 1.05 \\
\hline University of the Arts, London & 30 & 1.04 \\
\hline Queen Mary University of London & 26 & 0.89 \\
\hline The University of Hull & 25 & 0.88 \\
\hline Liverpool John Moores University & 25 & 0.86 \\
\hline
\end{tabular}




\begin{tabular}{|c|c|c|}
\hline Edge Hill University & 25 & 0.85 \\
\hline London School of Economics and Political Science & 24 & 0.83 \\
\hline The University of Warwick & 23 & 0.79 \\
\hline Cardiff University & 23 & 0.79 \\
\hline University of Derby & 22 & 0.77 \\
\hline Sheffield Hallam University & 22 & 0.77 \\
\hline The University of Bradford & 20 & 0.71 \\
\hline The University of Lincoln & 20 & 0.71 \\
\hline Birmingham City University & 19 & 0.67 \\
\hline The University of Surrey & 19 & 0.66 \\
\hline The University of Kent & 18 & 0.63 \\
\hline Aston University & 17 & 0.58 \\
\hline The University of Leicester & 15 & 0.53 \\
\hline The University of Northampton & 15 & 0.53 \\
\hline The University of Winchester & 15 & 0.52 \\
\hline University of Bedfordshire & 14 & 0.48 \\
\hline University of Hertfordshire & 14 & 0.48 \\
\hline The University of Essex & 14 & 0.48 \\
\hline University of Plymouth & 14 & 0.48 \\
\hline The University of Lancaster & 13 & 0.45 \\
\hline Leeds Beckett University & 13 & 0.44 \\
\hline The Royal Veterinary College & 12 & 0.43 \\
\hline The University of Greenwich & 12 & 0.43 \\
\hline The University of Reading & 12 & 0.4 \\
\hline Other Universities in UK England - South & 12 & 0.4 \\
\hline Brunel University London & 11 & 0.38 \\
\hline The University of Westminster & 11 & 0.37 \\
\hline Swansea University & 11 & 0.37 \\
\hline The Nottingham Trent University & $10<=$ & $0.37<=$ \\
\hline De Montfort University & $10<=$ & $0.37<=$ \\
\hline The University of Sussex & $10<=$ & $0.37<=$ \\
\hline The University of Wolverhampton & $10<=$ & $0.37<=$ \\
\hline The University of East London & $10<=$ & $0.37<=$ \\
\hline
\end{tabular}




\begin{tabular}{|c|c|c|}
\hline University of the West of England, Bristol & $10<=$ & $0.37<=$ \\
\hline University of Worcester & $10<=$ & $0.37<=$ \\
\hline University of Gloucestershire & $10<=$ & $0.37<=$ \\
\hline University for the Creative Arts & $10<=$ & $0.37<=$ \\
\hline Kingston University & $10<=$ & $00.37<=$ \\
\hline Other Universities in UK England - York & $10<=$ & $0.37<=$ \\
\hline The Manchester Metropolitan University & $10<=$ & $0.37<=$ \\
\hline Canterbury Christ Church University & $10<=$ & $0.37<=$ \\
\hline The University of Portsmouth & $10<=$ & $0.37<=$ \\
\hline The University of Central Lancashire & $10<=$ & $0.37<=$ \\
\hline Anglia Ruskin University & $10<=$ & $0.37<=$ \\
\hline Royal Holloway and Bedford New College & $10<=$ & $0.37<=$ \\
\hline Newman University & $10<=$ & $0.37<=$ \\
\hline Bath Spa University & $10<=$ & $0.37<=$ \\
\hline University of Cumbria & $10<=$ & $0.37<=$ \\
\hline Other Universities in China & $10<=$ & $0.37<=$ \\
\hline Other Universities in Ireland & $10<=$ & $0.37<=$ \\
\hline The University of Huddersfield & $10<=$ & $0.37<=$ \\
\hline Other Universities in UK England - North & $10<=$ & $0.37<=$ \\
\hline Other Universities in UK England - West & $10<=$ & $0.37<=$ \\
\hline Coventry University & $10<=$ & $0.37<=$ \\
\hline The University of Salford & $10<=$ & $0.37<=$ \\
\hline Other Universities non-UK (ambiguous) & $10<=$ & $0.37<=$ \\
\hline University of Northumbria at Newcastle & $10<=$ & $0.37<=$ \\
\hline Liverpool Hope University & $10<=$ & $0.37<=$ \\
\hline The City University & $10<=$ & $0.37<=$ \\
\hline University Campus Suffolk & $10<=$ & $0.37<=$ \\
\hline The University of Keele & $10<=$ & $0.37<=$ \\
\hline The School of Oriental and African Studies & $10<=$ & $0.37<=$ \\
\hline The University of Glasgow & $10<=$ & $0.37<=$ \\
\hline University of Chester & $10<=$ & $0.37<=$ \\
\hline Other Universities in Canada & $10<=$ & $0.37<=$ \\
\hline The University of Chichester & $10<=$ & $0.37<=$ \\
\hline
\end{tabular}




\begin{tabular}{|c|c|c|}
\hline Middlesex University & $10<=$ & $0.37<=$ \\
\hline London South Bank University & $10<=$ & $0.37<=$ \\
\hline Norwich University of the Arts & $10<=$ & $0.37<=$ \\
\hline Other Universities in UK England - East & $10<=$ & $0.37<=$ \\
\hline Other Universities in Netherlands & $10<=$ & $0.37<=$ \\
\hline Oxford Brookes University & $10<=$ & $0.37<=$ \\
\hline The University of St Andrews & $10<=$ & $0.37<=$ \\
\hline Other Universities in UK England - South & $10<=$ & $0.37<=$ \\
\hline Other Universities in UK (ambiguous) & $10<=$ & $0.37<=$ \\
\hline Bangor University & $10<=$ & $0.37<=$ \\
\hline The University of Bolton & $10<=$ & $0.37<=$ \\
\hline Conservatoire for Dance and Drama & $10<=$ & $0.37<=$ \\
\hline Teesside University & $10<=$ & $0.37<=$ \\
\hline The University of Aberdeen & $10<=$ & $0.37<=$ \\
\hline Other Universities in Germany & $10<=$ & $0.37<=$ \\
\hline Aberystwyth University & $10<=$ & $0.37<=$ \\
\hline The Arts University Bournemouth & $10<=$ & $0.37<=$ \\
\hline Cardiff Metropolitan University & $10<=$ & $0.37<=$ \\
\hline Other Universities in South Africa & $10<=$ & $0.37<=$ \\
\hline Bishop Grosseteste University & $10<=$ & $0.37<=$ \\
\hline Goldsmiths College & $10<=$ & $0.37<=$ \\
\hline Other Universities in UK Wales & $10<=$ & $0.37<=$ \\
\hline Staffordshire University & $10<=$ & $0.37<=$ \\
\hline York St John University & $10<=$ & $0.37<=$ \\
\hline London Metropolitan University & $10<=$ & $0.37<=$ \\
\hline Other Universities in Pakistan & $10<=$ & $0.37<=$ \\
\hline The Liverpool Institute for Performing & $10<=$ & $0.37<=$ \\
\hline Ravensbourne & $10<=$ & $0.37<=$ \\
\hline The Open University & $10<=$ & $0.37<=$ \\
\hline Leeds College of Art & $10<=$ & $0.37<=$ \\
\hline Other Universities in France & $10<=$ & $0.37<=$ \\
\hline Leeds Trinity University & $10<=$ & $0.37<=$ \\
\hline Trinity Laban Conservatoire of Music an & $10<=$ & $0.37<=$ \\
\hline
\end{tabular}




\begin{tabular}{|l|l|l|}
\hline Writtle College & $10<=$ & $0.37<=$ \\
\hline Other Universities in South Korea & $10<=$ & $0.37<=$ \\
\hline The University of West London & $10<=$ & $0.37<=$ \\
\hline Royal College of Music & $10<=$ & $0.37<=$ \\
\hline Other Universities in Japan & $10<=$ & $0.37<=$ \\
\hline University of London (Institutes and ac & $10<=$ & $0.37<=$ \\
\hline The University of Sunderland & $10<=$ & $0.37<=$ \\
\hline The Queen's University of Belfast & $10<=$ & $0.37<=$ \\
\hline Other Universities in the United Arab Emirates & $10<=$ & $0.37<=$ \\
\hline Falmouth University & $10<=$ & $0.37<=$ \\
\hline Other Universities in Singapore & $10<=$ & $0.37<=$ \\
\hline Roehampton University & $10<=$ & $0.37<=$ \\
\hline Other Universities in Lisbon & $10<=$ & $0.37<=$ \\
\hline Other Universities in Hungary & $10<=$ & $0.37<=$ \\
\hline Southampton Solent University & $10<=$ & $0.37<=$ \\
\hline The University of Dundee & $10<=$ & $0.37<=$ \\
\hline Royal College of Art & $10<=$ & $0.37<=$ \\
\hline Other Universities in UK England - North & $10<=$ & $0.37<=$ \\
\hline Other Universities in Spain & $10<=$ & $0.37<=$ \\
\hline Other Universities in Australia & $10<=$ & $0.37<=$ \\
\hline University of Wales Trinity Saint David & $10<=$ & $0.37<=$ \\
\hline Other Universities in Switzerland & $10<=$ & $0.37<=$ \\
\hline Total & 2,888 & 100 \\
\hline No= $==$ \\
\hline
\end{tabular}

Notes: $\mathrm{N}=2,888$ are the pupils from the total 5,194 who provided a top choice university. Only 2,678 pupils of the 2,888 had a successful NPD link. Final student weights applied. Sample sizes less than 10 rounded. 